University of Rhode Island

DigitalCommons@URI

Open Access Dissertations

1995

\title{
Our Beloved Lizzie; Constructing an American Legend
}

Gabriela Schalow Adler

University of Rhode Island

Follow this and additional works at: https://digitalcommons.uri.edu/oa_diss

\section{Recommended Citation}

Adler, Gabriela Schalow, "Our Beloved Lizzie; Constructing an American Legend" (1995). Open Access Dissertations. Paper 494.

https://digitalcommons.uri.edu/oa_diss/494

This Dissertation is brought to you for free and open access by DigitalCommons@URI. It has been accepted for inclusion in Open Access Dissertations by an authorized administrator of DigitalCommons@URI. For more information, please contact digitalcommons-group@uri.edu. 


\section{OUR BELOVED LIZZIE; \\ CONSTRUCTING AN AMERICAN LEGEND}

BY

GABRIELA SCHALOW ADLER

A DISSERTATION SUBMITTED IN PARTIAL FULFILLMENT OF THE REQUIREMENTS FOR THE DEGREE OF

DOCTOR OF PHILOSOPHY

IN

ENGLISH

UNIVERSITY OF RHODE ISLAND

1995 


\section{DOCTOR OF PHILOSOPHY DISSERTATION \\ OF}

GABRIELA SCHALOW ADLER

APPROVED:

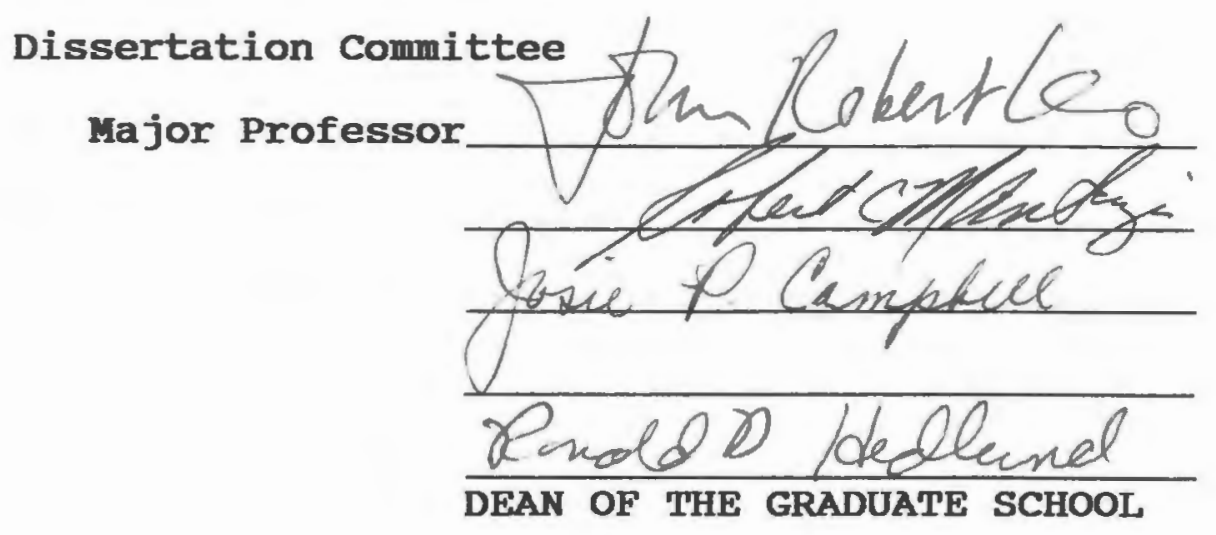

UNIVERSITY OF RHODE ISLAND 


\section{ABSTRACT}

Lizzie Borden is a legendary figure in American culture who, unlike some others, has not received much scholarly attention. Yet her story has generated a great number and variety of texts, and several performance pieces as well. New texts continue to be published. This body of work begs to be examined, so that insights may be gained into the interactions of popular literacies and narrative forms. The study of different textual treatments of the same subject allows us to trace issues of gender, class, family, the construction of subjectivity, and the intersections of genre, narrative and history.

The theoretical approach is presented in the introduction. It draws on a range of perspectives, from feminist, new historicist, and poststructuralist, to biography, genre, film and media, and folklore studies, and from the ideas of Mikhail Bakhtin. An attempt to see how popular texts produce social knowledge requires such an interdisciplinary approach. These theories act as lenses through which the many representations of Lizzie over a century can be viewed and analyzed for their significance. The study is genre-centered, with chapters on biographical texts, journalism, and "creative" texts such as novels, short stories, poems, plays, and a television film. Each form is described and explored for its characteristics and 
how it creates or recreates this legendary figure.

One of the most striking features that emerges from this close reading of a century of Borden texts is their level of complexity. One might suppose that there is not much substance to Lizzie Borden, a pop culture icon immortalized in a rhyme, but the texts prove otherwise. They are marked by intertextuality; they borrow from each other, speak to each other, help to shape each other. They also construct readers, and readers construct them. Each text bears the traces of its time. In it are implicated specific cultural concerns and anxieties which tell as much (and sometimes more) about that particular society as about Lizzie Borden. Thus, the study of popular texts can be as rich and revealing as that which focuses on more conventional, canonical literary works. 


\section{ACKNOWLEDGMENT}

Although this should be the easiest part, I find it difficult to adequately express my gratitude to the people who helped me reach this goal. My major professor, John Leo, deserves undying thanks for his uncanny ability to always push me in productive directions, to offer brilliant critiques, to encourage me, to keep me on track, and to keep me laughing. Along with Professor Leo, the other members of my original committee, professors Josie Campbell, Robert Manteiga, (and until his departure from the University) David Stineback, had seen me through the M.A. degree. I was overjoyed when my "dream team" agreed to sign on for the next phase. Their guidance has proven invaluable. When we needed an additional member for the defense, Professor Lois cuddy graciously agreed to participate. I appreciate the thoughtful comments, questions, advice, patience, and good humor of these professors more than I can say. In her role as Director of Graduate Studies, Dr. Cuddy helped me in so many ways through the bureaucratic maze, and I will always remember her kindness. I am also grateful to Professor Sharon strom for chairing my defense.

A note of thanks goes to Professor Jules Ryckebusch, my colleague at Bristol Community college. He made some terrific "Lizzie events" (conference, PCA session) possible, 
and did so in his characteristically generous style. He also lent me hard to find books and offered helpful commentson my journalism chapter.

I also want to thank my parents, Mrs. Wanda Schalow, and the late Mr. Otto Schalow, who both worked so hard to give me the opportunities which were denied to them. They encouraged me in every endeavor, and any success I have is theirs as much as mine.

Finally, thank you to my husband, Arnie, for his unfailing support (moral and technical when computer emergencies arose), patience, and sense of humor which helped me keep things in perspective. In every way, he proves himself my dearest friend. Dedicating a dissertation about an alleged axe murderer poses rather a delicate problem. To ensure it is taken in the proper spirit, we must move from one area of pop culture to another, and with the Shirelles sing the immortal line:

"This is dedicated to the one I love." 
TABLE OF CONTENTS

\section{Chapter One}

Introduction...........................

Chapter Two

The Historical Lizzie:

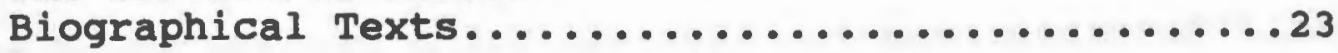

Chapter Three

Media Frenzy:

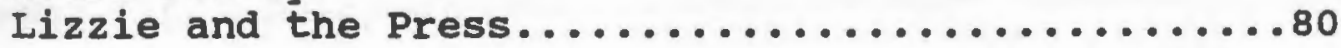

Chapter Four

Looking at the Many Faces of Lizzie:

Textual Fabulations and Speculations............100

Afterword................................ 162

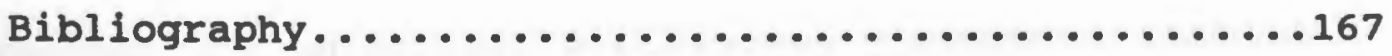




\section{CHAPTER ONE}

\section{INTRODUCTION}

"There is that in the tidings of a murder that thrills the human heart to its depths." Hosea M. Knowlton

On August 4, 1892, Lizzie Borden of Fall River allegedly took an axe, and made an enduring place for herself in American culture. She may appear to be a rather unorthodox subject for a literature dissertation. Lizzie never published any "literary" work, or anything at all, and the books written about her have not been declared "great" or included in university literature courses. Yet the time seems right to study her, in part because academic literary discourse has become more inclusive. For example, Mary Poovey argues for cultural criticism, which shifts from privileging traditional canonical literary texts to treating as significant the larger social formation which produces a variety of texts, not to mention the exclusions and repressions which mark a universal phenomenon such as "literature." Now, also, developments in theory provide useful lenses through which to view Borden texts. I will discuss my theoretical approach shortly, but first let us look briefly at the "Lizzie phenomenon."

Not only does her case continue to enthrall lawyers, it also fascinates people from many walks of life. For over a 
century, the figure of Lizzie has infiltrated numerous areas of American popular culture. Many of us learned to chant the famous rhyme, "Lizzie Borden took an axe" as children. As recently as 1992, a piece in the New Yorker played on our familiarity with the Fall River legend to characterize the state of New York politics. It substituted Liz Holtzman for Lizzie in a paraphrase:

Lizzie Holtzman took an axe.

She gave Geraldine forty whacks.

When Bobby Abrams saw what she had done,

He took the axe and gave her forty-one.

The reporter attributes these lines to senator Alphonse D'Amato (Logan 46). I suspect that her fame will outlast the politicians. Her regional popularity is immense. In Rhode Island, the popular cartoonist Don Bousquet spoofed the Elvis stamp contest held by the U.S. postal service, by presenting a choice between "good Lizzie" and "bad Lizzie" stamps. Last year, two disk jockeys on morning radio in Rhode Island did a routine with Elvis calling in about his postage stamp. He claimed to be a distant relative of Lizzie's, and confided that her stepbrother Elvis Borden had actually committed the murders, not with an axe but amphetamines. One of the most popular restaurants in Fall River is "Lizzie's," just one block north of the former Borden house on Second street. The Fall River Historical Society has embarked on a tasteful marketing campaign, to 
sell Lizzie Borden tee shirts, mugs, calendars, and books. Her presence is also evoked in numerous television narratives, whenever an axe murderess lurks.

These references to Lizzie act as one-dimensional markers, pointing to a more detailed and complex character. She exists in popular novels, biographical true crime accounts, poems, short stories, and plays, and is the subject of a television movie. Even opera and ballet offer versions of this widely dispersed American legend. As a testament to the global reach of American popular culture, she is also known in Britain and Japan. A flyer from England recently came my way, announcing the appearance of "elegant monologist Gloria Wood," who performs on both sides of the Atlantic in "The Lizzie Borden story." I did not think that performers like Miss Wood, who seems of another era, still practiced their craft, but evidently she is still in business. Perhaps the oddest manifestation is Lizzie Borden in a Japanese book of Mother Goose rhymes. Robert Flynn's bibliography contains a reproduction from the text, showing the graceful Japanese letters of the rhyme above a line drawing of a frowning woman, running and holding up a large axe. The slippages and congruencies in the cultural crossover would make an interesting study in themselves, but my focus here is almost entirely on the American scene, with a couple of inclusions from England and Canada. The key point here is the tenacious hold her figure has had on the 
popular imagination for all these decades.

One is compelled to wonder why. After all, she was not the first woman accused of murdering members of her family. Axe murders were not rare occurrences in the nineteenth century. In fact, there was another axe murder in the Fall River area at the same time as the Borden murders, but it did not capture our fancy. Finding other accounts of such crimes is remarkably easy. I came upon one by chance, while looking at a New York Times microfilm reel. In the September 1, 1879 paper there is a brief account of william Engler's attack on his neighbor. Mr. Engler, insanely jealous of his 250 pound wife, let the unfortunate John Cummings have it when he suspected him of being after his beloved. The passionate Engler and scores of others have vanished into obscurity while Lizzie endures in the public sphere. I am not sure that all the reasons for this will emerge from my study, but some will be suggested.

More importantly, I will be looking at how this figure has been constructed in a variety of texts and over a number of years. I do not attempt to be comprehensive, but certainly include all the major as well as many lesser examples in my discussion. I hope to gain an understanding of how genres produce a hero/villain; how textualizations produce the public sphere, and how they are produced by it. I am not concerned with solving the Borden murders, or arguing for Lizzie's guilt or innocence. Rather than 
viewing the texts from one perspective only, I will draw on literary, historical, cultural, and gender studies to consider the issues that arise.

one of the initial and key questions that presents itself is the nature of the public sphere in which the Borden legend is perpetuated. The audience and its circumstances certainly have changed in the course of a century, yet the fascination with Lizzie continues. Not surprisingly, the textualizations of Lizzie bear the markings of the times in which they were generated. Although successive texts draw on those which preceded them, they also treat the characters and events in ways that address the changing interests and concerns of audiences. A novel presenting a lesbian Lizzie hardly raises eyebrows in the 1980s, but was unthinkable in the 1930s, at least for popular consumption.

Susan Douglas points out that scholars do not have much data to work with, regarding media audiences. There is more speculative than solid information, but some of the ideas about audiences are worth considering. For example, she reiterates that one of the central presuppositions for contemporary theory "dismisses any notion of the unified subject or self." It is possible for people to assume a number of subject positions, even contradictory ones, depending on the medium and message (130). Thus, Lizzie Borden could attract fans who view her from a variety of 
perspectives, from benign amusement to horrified fascination to outraged defense. Revulsion and attraction could reside in the same consumer.

Another crucial presupposition that Douglas cites nemphasizes the way media texts themselves, especially when viewed by subcultural groups, invite and incite oppositional, resistant readings that challenge the more hegemonic codes of popular culture" (130). From this standpoint, some members of the audience, including some of the writers on Lizzie, very likely see her as the victim of patriarchal oppression who is driven to bloody rebellion. Others are convinced that the popular belief that she is guilty is misguided. However one approaches her, it must be emphasized that parricides do not meet with approval in our culture, and yet she is a figure we seem comfortable with. She is our very own axe murderess with whom we are cosily familiar. My look at the various constructions of Lizzie over the years will provide, I hope, more detail about the diverse readings of this odd figure who has assumed an odd position in our consciousness.

Lizzie seems to strike an endlessly subversive chord in our culture. If she is a feminist heroine, she is hardly as morally superior as some feminists like to envision their gender. After all, she killed poor old Abby, too. If she is a vicious murderess and irredeemably evil, how do we account for her unblemished reputation and many acts of 
generosity? If she is an innocent, loving daughter, what about the likelihood that she killed her old father as he slept? If she was guilty, why wasn't she convicted? If she embodies a critique of capitalism, why did she revel in her inherited wealth? If she was a greedy, rich woman, why was she known for her generosity? If her significance transcends her position as a citizen of Fall River, why was she such an ordinary woman, indistinguishable from the other spinsters in town? And if she was so dull and ordinary, why is she a legendary figure?

Attempts to pin her down are invariably accompanied by the collapse of traditional binary oppositions and a dizzying sense of the instability of a figure we think we know so well. Lizzie challenges boundaries in several ways, beyond the alleged act of murder. The texts about her raise questions about boundaries between literary genres-biography (fact) and fiction (imagination). They challenge the separation of "highbrow" art from mass culture, and the notion of what constitutes a proper subject of study in the academic sphere.

As we consider the diverse readings and reactions Lizzie inspires, we need to address a question implicit in the discussion of audience, that of identification. Does the audience identify with Lizzie or with her victims? Since I have already alluded to the diversity in the audience and a paucity of data, that question cannot be 
answered in a brief or simple way, but it is important.

Much theorizing about audiences exists in film studies, and developments there have a bearing on how we might view the audiences which turned their attention to Lizzie Borden. some influential theorists hold that identification is gender-based. Carol Clover's study of American horror films challenges this view, and entertains the "possibility that male viewers are quite prepared to identify not just with screen females, but with screen females in the horror-film world, screen females in fear and pain" (5). This runs contrary to much film theory and cultural analysis. Laura Mulvey posits a cinematic gaze "structured by male or masculine perceptions." clover questions these assumptions about a mastering gaze ( 8 ). She disagrees that males in the audience identify only or mostly with males onscreen, and females in the audience with their counterparts onscreen (20). She makes the point that "the relation between camera point of view and the processes of viewer identification is poorly understood," and that much shifting of multiple subject and/or identificatory positions may go on (45). These ideas about the horror film audience seem to me largely applicable or transposable to Lizzie's audience. The legend, after all, has the trappings of a horror story. But further, the variety of responses to Lizzie and the versions of Lizzie suggest that identification is not a matter of applying a simple formula, gender-based or 
otherwise. There are men and women who may identify with Lizzie, and those who may identify with the victims, and some may shift from one to the other. The particular representation of Lizzie would have much to do with a reader's position, and I do not think it is easily predictable. Where does this leave us? I will make no claims to certainty, preferring to emphasize the fluidity of this question.

Although accounts of Lizzie appear in various genres, the one that stands out is biography. The most significant and influential books, by Pearson, Porter, and Lincoln, are all part of a biographical sub-genre, the true crime narrative. Biography influences all the other texts, for it is the path we all take toward Lizzie. She was, first and foremost, a real, historical person who left material traces behind. What we make of her life, however, is not as simple as this elementary fact. Biography involves more than the narrative of someone's life. As a literary form, it has provoked a variety of viewpoints and theories. In fact, Valerie Ross points out that for much of the twentieth century biography has suffered considerable repression in literary studies. The academic profession has repeatedly dismissed "biography, the feminine, and the popular--these three being nearly inextricable in 19th-century academic reception" (137-8). (They look like the three prime reasons to dismiss any study of Lizzie Borden.) Ross claims further 
that biography "has since the formalization of departments of literature been granted no legitimate place in academic literary discourse" largely because of gender bias (156). This is changing, however. In recent years, there have been considerable interest and activity in this genre, as an outgrowth of feminist scholarship. Traditional views have been revisited and challenged. The contributions of contemporary critical theory are worth noting, as is the rather interesting situation regarding the audience for biography, which Sharon O'Brien recognizes. There is a tremendous gap between general readers and academics in terms of their expectations about biography and epistemology. Most readers expect a biography to tell the "truth" about the subject, to avoid interpretive frameworks, and to uncover the story that already exists (123-4). Not only do many consumers of texts hold this view, but also some producers. The poet Ruth Whitman, herself an academic, takes a traditional approach to biography. In an article discussing the writing of the historical persona poem, specifically her poem about Lizzie, she states her aim "to reveal the essence of a well-known historical character" (66). This presumes that this essence is stable and recoverable.

However, as O'Brien points out, developments in contemporary theory have led many critics to question not only the concept of the self "as a unified, knowable, and 
recoverable entity," but also the transparency of language, and even "the explanatory power of narrative" (123). This last may help to account for the tendency of these provocative ideas often to be expressed in tedious and nearly unreadable form, and of no interest to those general readers who are deeply committed to the genre in question. David Lodge states with refreshing irreverence that much theory is "the demonstration of a professional mastery by translating known facts into more and more arcane metalanguages." This is not all bad; reading it "sharpens the wits and tests the stamina" (Lodge 8 ), perhaps something akin to old Father William arguing the law with his wife. He further observes that "since literary criticism was virtually monopolized by the universities, it has become of all-absorbing interest to its practitioners and a matter of indifference or incomprehension to society at large" (175). He is right, and it is a pity that this is so, because as O'Brien's discussion makes clear, theories of biography provide insights into the genre and how we read and write it. She points out the contradictory strains in traditional biographical practice where the subject's essence is conveyed, but in the form of a story, using novelistic techniques. The biographer looks to realism as a model, and the "assumptions about biography accord with those made by the readers and writers of realistic fiction." Language is seen as a reliable method of representation, the 
chronological plot works to order reality, and the author is a narrator who can be trusted (124-5). In other words, this form of biography is not something which naturally occurs, but is the result of a particular set of beliefs about the world.

other theorists go so far as to "question the very existence of biography as a genre" because of serious questions about the nature of the self (125). O'Brien grapples with this issue, citing some attempts by others to create a genre consistent with theory, and her own suggestions for writing which avoids the unified or essential self. She envisions a feminist model which challenges the "still coherent form" of biography, without dispensing with "the pleasures of narrative" (131). I wonder if this can be accomplished. I also wonder how one can question the existence of a genre which remains immensely popular, its manifestations regularly on the best seller list. And yet, the critique of realism and of the unitary subject is necessary and even illuminating. It is crucial to my readings of the Borden texts. Any coherent analysis of writing must be grounded in some kind of theoretical framework, whether it is stated or not, and whether it is expressed gracefully or obscurely. Oddly enough, a survey of these texts, mostly traditional examples of literary genres, makes the argument against the unitary self far more effectively than an avant-garde text might. 
As one reads on, one encounters different versions of Lizzie (sometimes in the same text), all said to be true. The more one finds out about her, the less one knows her. This state of affairs only begins to make sense when one questions the old assumptions about biography.

And why stop there, when history presents similar problems and is so closely related to biography? As O'Brien observes, history as well as biography has been challenged by contemporary theory in terms of its epistemological base (123). How do we even begin to think about the past--how to know it, recover it, and derive meaning from it, in the light of doubts raised about all of these points?

An approach which I find useful here is what is termed the "new historicism." This body of theory has extended beyond Renaissance studies to encompass various periods. The fact that "much new historical analysis involves ideological unmasking that exposes the historical constructedness of ideas and beliefs" (Thomas xii) makes it a helpful guide when examining Borden texts. In terms of literary studies, new historicism interrogates representation and argues against isolation from other historical forces (xiv-xv). Rather, it emphasizes the "sociocultural field at the text's moment of production (rather than its moment of reception)" (Dimock 602). As with any school of theory, there are disagreements and divergences among its practitioners. Wai-Chee Dimock's 
critique of new historicism includes a concern with this exclusion of the reader, and she points out that feminist new historicists "have been very attentive to the figure of the reader" (603). As my earlier discussion of audience indicates, I consider this part of the communication equation important as well. According to Dimock, there are "readers and readers... and, when we meditate on their points of divergence as well as their points of coincidence, when we think about their uneven genesis, conflicting identities, and different modes of reception," we will have to rethink "history" as "something less than homogeneous...less than synchronized." viewing history in this way allows us to see its "textuality." Not only does this mean that history cannot be recovered as a "lived totality," but it has a "sedimented, non-uniform, and therefore untotalizable texture." It is marked by "uneven velocities and shifting densities of social change" which can be placed into a single posture only "through an act of historical repression" (615). Several decades of Borden texts bear this out, as social and cultural concerns influence shifting representations of Lizzie.

The textuality of history is also of paramount concern to Carroll Smith-Rosenberg, a historian whose attention to questions of class and gender is helpful. She views class beyond "its relation to production," as "a series of relationships, of culturally constructed identities." It 
is, then, "a complex exchange between economic forces and cultural identity," and she argues that this is a crucial element when viewing nineteenth-century Americans in class terms. Other historians claim that "consensus, not class, characterized 19th century America." It seems to me that she makes a good case for class considerations, which are significant when we examine the world Lizzie Borden lived in. Smith-Rosenberg singles out two myths which middleclass men used to rationalize their identity in early nineteenth-century America--"the Myth of the Common Man" and "the cult of True Womanhood." One "denied class, the other constructed its elaborate etiquette." Their apparent opposition and actual interdependence "illustrate the ways in which difference, even contradiction, lies at the heart of class identity" (34). This is useful to keep in mind when surveying the class issues embedded in the Borden case, and the contradictory nature of so much of the case and responses to it.

For Smith-Rosenberg, words, like class, are cultural constructs, from which we create a sense of self and of agency. And society is marked by a multiplicity of "languages" rising from diverse experiences of gender and class (35). She acknowledges the influence of Bakhtin's theories here, which I will discuss further shortly. His Iinguistic model, a struggle between "the forces of linguistic diversity" and the need of every society for 
"unitary language" provides the cultural historian with insights into how language "both serves and wars against the unifying forces of class cohesion" (36). So, to gain understanding of these functions, we must look at narratives. And history itself is a "narrative of narratives" (31).

Narrative is viewed by critics as a problematic form, and by general readers as anything but, when it flows smoothly. A reader uninterested in theory (a Borden fan, perhaps) might wish to dismiss all this, but a look at several tellings of Lizzie's story illustrates how questions can be raised which the discussion of narrative might illuminate. There is the question of genre and reliability. Hayden White, for example, concludes "that the writing of history has little to do with such qualities as true or false... and that ultimately historical writing cannot be distinguished from fiction" (Lutzeler 33). Others disagree, as do I. Käte Hamburger states that "while fiction has at its basis the so-called as-if structure, and thus proves to be pretense, illusion, and unreality, historiography always relates to actual events" (Lutzeler 34). The strong fictional slant of some of the biographical Borden texts would seem to vindicate White's view, but I cannot subscribe to it. However, it is difficult to see a neat division between fiction and historiography. Indeed, as Lutzeler says, in both areas, "narration has fallen into a state of 
permanent crisis" (30).

And both perspectives on narrative structure and effect have important points in common. They work to structure identity of "a generation, a nation, or a culture," and they do it with stories. "During an identity crisis society may show greater interest in historical remembering... or demand a more fictional provision of identity." In any case, historical and literary consciousness involve past (memory), present, and future, and narration is marked by these dimensions (39).

Narrative may be in crisis from a critical standpoint, but it also enables people to cope with crisis. Amma Davis studied the reactions of people to murders in a small Texas city in 1987, and drew interesting conclusions, some of which are relevant to the Borden case. She found that the community dealt with its fears through legend and rumor, thus illustrating "the power of narrative to contextualize otherwise meaningless events" (99). People were in a state of near panic at first, which was also the case in Fall River. Then, stories emerged--cautionary stories and stories of accusation. Some involved outsider figures, a common feature of folktales and legends (102). In Fall River, mysterious strangers were spotted, and Arnold Brown recently created a whole new theory about the murders based on this premise. There is also the irony that lizzie, very much an insider as a member of the Yankee elite, was also 
perceived as odd and peculiar--an outsider. In Texas, people were unnerved by the randomness of the murders, and their stories displaced these fears "to a more restricted frame, horror of domestic violence" (104), which happened in Fall River as well. In these situations, "folklore acts as the unconscious creative reaction by the collective entity of the group in response to a stressful change in its environment." It allows the monstrous experience to be identified and embodied, and the anxiety to be shared (108). A similar process was at work in Fall River, and it continues. What we have to wonder is how much of this became transformed into historical data which authors drew on for their texts.

Another way to see this is as an example of heteroglossia, a term used by Mikhail Bakhtin for "linguistic centrifugal forces and their products." He saw the cultural world traversed by "centripetal (or 'official') and centrifugal (or 'unofficial') forces. The former seek to impose order on an essentially heterogeneous and messy world; the latter either purposefully or for no particular reason continually disrupt that order" (Morson 30). Bakhtin discusses heteroglossia as an element in stylistics of the novel, but I find his ideas have a wider application to cultural criticism. So, seen in these terms, the government and the courts and the Establishment of Fall River sought to impose their meanings on the Borden case, but the people 
provided several others. The "social diversity of speech types" (Bakhtin 263) and the clamor of many voices are important factors in the Borden texts which will be discussed in this study.

another pertinent feature of Bakhtin's thought is the representation of the individual in the novel, and unfinalizability. In the epic genres, the individual is distanced, and "is a fully finished and completed being." In novelistic discourse this distance disappears, as the individual has contact with the present. This radical change was affected by folklore and "popular-comic sources," which introduced laughter into the picture. Laughter allowed the "image of man" to be investigated, exposing "the disparity between his surface and his center." "A dynamic authenticity was introduced into the image of man, dynamics of inconsistency and tension between various factors of this image; man ceased to coincide with himself, and consequently men ceased to be exhausted entirely by the plots that contain them" (34-5). This is a different and fruitful way to look at representations of character, and helps to explain why an important writer like Edmund Pearson cannot, despite his skill, present a complete, coherent Lizzie Borden. For Bakhtin, "an individual cannot be completely incarnated into the flesh of existing sociohistorical categories." The reality represented in the novel "is only one of many possible realities; it is not inevitable, not 
arbitrary, it bears within itself other possibilities" (37). This dynamism and creative messiness extend into considerations of genre. In historicizing the novel, Bakhtin points to connections with "extraliterary genres," its use of "letters, diaries, confessions" and so on. Thus, nthe novel often crosses the boundary of what we strictly call fictional literature," since "the boundaries between fiction and nonfiction, between literature and nonliterature and so forth are not laid up in heaven. Every specific situation is historical. And the growth of literature is not merely development and change within the fixed boundaries of any given definition; the boundaries themselves are constantly changing" (33). Seen from this perspective, the presence of what may be termed a range of "artistic" and "popular" texts, and fictional biographies and biographical fictions in the Borden textual landscape is not so much troubling as a sign of cultural vitality which challenges and provokes the reader.

Bakhtin's ideas about ethics and literature are also pertinent to considerations of Borden texts. Lizzie owes her notoriety to a pair of sensational murders, and I am convinced that one of the continuing attractions of her story (or more accurately, stories) is the ethical question. It is not only a matter of did she or didn't she do the deed, but if she did, what was the extent of her guilt. For Bakhtin, "novels...occupy a special place in education." 
They act as "powerful tools for enriching our moral sense of particular situations." But Bakhtin refuses a simplistic, universalizing moral vision. For him, "all approaches to ethics in terms of rules not only ignore essential particulars that fail to fit a rule, but also function in a fundamentally mechanical way." This does not mean surrendering to relativism. If ethics "is located fundamentally in particular situations, then real work is always required" (Morson 25-7). The varied ways authors have imagined Lizzie's story, and the way Borden fans keep the seemingly endless conversation about her going, illustrate the power of the ethical issues involved, in a very particular sense.

Underlying all of Bakhtin's work is an emphasis on the social. In a conversation he had near the end of his life, he spoke about his book on Dostoevsky, dismissing some of his interlocutor's praise: "All that is merely literary criticism...there has to be a way out that leads to other worlds" (Bocharov 1013). He wrote, "to be means to communicate;" it means to "be for another, and through another for oneself. A person has no sovereign internal territory, he is wholly and always on the boundary; looking inside himself, he looks into the eyes of another or with the eyes of another" (Morson 50-1). For Bakhtin, "the listener (real or imagined) shapes the utterance from the outset" (129). Nor does he neglect the author. In fact, 
Lodge speculates that Bakhtin's greatest contribution to contemporary criticism is "to have made a timely reaffirmation of the writer's creative and communicative power." Literary theory has nearly banished the author, but non-academics have not (7). While I appreciate other contributions of Bakhtin more than this one, I will be paying attention to authors. Looking closely at some of these people who wrote about Lizzie provides insights into their texts which would be missed if we dismissed them as mere "scriptors." For example, the fact that Pearson was a boy in 1892, became a true crime writer, and was obsessed with Lizzie is significant. Authors, audiences, social conditions and issues will all be considered here.

For a student grinding away at a dissertation, Bakhtin's way of seeing is also a consolation. He reminds me that what seems like a lonely endeavor is filled with voices--of Borden texts, of their imagined and real audiences, of critics' texts, and of my imagined and real audiences. We even outnumber the crowd that stood, thrilled and terrified, outside the house on second street on those early August days in 1892 . 
CHAPTER TWO

THE HISTORICAL LIZZIE: BIOGRAPHICAL TEXTS

Edmund Lester Pearson was not the first to publish a book about Lizzie Borden, but he was the most influential in shaping and popularizing the Borden legend in the early decades of this century. Most of his books are currently out of print, but in his day Pearson was an immensely popular writer. The standard reference book Twentieth Century Authors cites him as having "an international reputation as the foremost American writer on celebrated crimes...certainly the most readable." He is also mentioned in another biographical sketch in the same book, where he is quoted as a respected authority. His response to Mrs. Marie Belloc Lowndes' fictionalized representation of the Jack the Ripper case is to declare it "the best book about murder written by any living author." It seems, then, that he enjoyed reading widely in the crime literature, as well as producing it. In fact, after he died, his library of approximately two thousand books, mainly on criminology, was purchased by the New York Public Library (Walbridge).

Pearson's crime books all follow the same format, in which several important cases are described and analyzed in his characteristically breezy and entertaining manner. Oddly enough, Lizzie Borden appears in all four, and is the 
sole subject of his final volume, The Trial of Lizzie Borden. In the first book, studies in Murder, the Borden case is the opening chapter, and by far the longest. This is considered his best known work, and in 1938 it was included in the Modern Library. It has been recognized as "a pioneer book in its field, as least in the United States," with a "literary distinction" lacking in other books of the genre. He is credited with introducing "the then still living Lizzie Borden to a new generation" (Walbridge). His Trial of Lizzie Borden became the first volume of the Notable American Trials series ("Pearson, Edmund Lester"). The other two books fed the interest he had created in Lizzie, as well as carrying on in a genre that proved so successful for him.

One way to get an idea of just how successful and popular Pearson's books were is to check old volumes of Book Review Digest. A book that is widely reviewed is likely to have a large readership. And a book reviewed in a standard library journal such as Booklist (as four are), stands to be purchased by many public libraries. There is no accurate way to determine how many people read these books, but widespread and generally favorable reviews suggest that the numbers would be high. Studies in yurder was reviewed in at least 19 publications, including Saturday Review, New Statesman and a host of newspapers, from the New York Times to papers in Boston, Cleveland, Greensboro, St. Louis, and 
springfield. Five Murders got at least nine reviews, More studies in Murder five, Murder at Smutty Nose four, and prial of Lizzie Borden nine, including TLS (London). In addition, Robert Flynn, a publisher, antiquarian book dealer, and Borden expert, tells us that many of Pearson's essays were reprinted in various crime books over the years (33). Clearly, anyone looking for a rollicking good crime story to while away the hours in the $20^{\prime} \mathrm{s}$ and 30 's could turn to Pearson and thus come face to face with Lizzie Borden. But who were these people who, by picking up these books, contributed to the making of a legend? We can only speculate.

Writing in 1976, John Cawelti bemoans the "lack of solid data about audiences for the various formulas" (story types) (298). An earlier work published in 1929 by william s. Gray expresses the same frustration. He attempts to report on reading interests nationwide, using various studies. Actually determining what adults read is "practically impossible," since the studies and the groups have been so diverse $(40)$. He does find that for the period, which includes some of Pearson's books, women on average read twice as many books as men, urban residents read more than rural people, and the number of books read per year rises with the level of education (32-35). So we may presume that Pearson's audience would include more women, urban residents, and generally educated people. 
However, Gray also tells us that reading habits vary widely in different sections of the country (260), and interests and motives of readers are quite diverse (268).

one might hope for more specific information in Asa Dickinson's 1937 list of the "best books" of 1926-1935. However, this compilation of four hundred books was "selected by a consensus of expert opinion as most worthy the attention of intelligent American readers" (xi). Pearson's books are absent from this august group, as notably are all crime and detective stories, which the experts evidently considered unworthy. Biographies are included, but only of "great" and famous figures, such as Queen Victoria and Dickens, with no trace of the infamous. This list is telling, in that it shows how little attention the intellectual elite was paying to popular culture except to excoriate its manifestations. But the public was reading crime books, even if the guardians of culture disapproved or ignored them. James Hart states that in the 1920s and 30 s detective and mystery stories were popular. He does not specify true-crime stories, but they are close enough in type to let us assume they are included as well. Public library membership was increasing, especially during the Depression. It gave readers cheap access to books they might not otherwise buy, and read only once. The public moods he describes lend themselves quite favorably to appreciating Pearson's books. The generation 
of the 1920's "was disillusioned about the past and cynical about the present with its commercial coolidge." It was scornful of American culture and hypocrisy. With the Depression, many people became critical of the capitalist system, which had brought disaster. Reading mysteries and detective stories offered a chance to relax and concentrate "on a problem removed from their daily lives" (230-59). The Borden case was removed enough in time to provide the distraction of a bygone era, but close enough to satisfy the cynics. It offers a jaded audience the seamy side of the proper victorian family scenario: miserly capitalist father is struck down by genteel, churchgoing daughter, and she not only gets away with it, but inherits his wealth. The public clearly seemed ready for Pearson's version of Lizzie Borden, and after it accepted her, even began elaborating on her and producing representations of her, some of which were sent to Pearson, as I will describe in more detail later.

Before we examine the picture he presents to readers, it is important to consider his rather peculiar "relationship" to Lizzie. Why the unrelenting obsession with this cipher of a woman who lived in quiet seclusion, shunning all publicity?

Pearson begins Eive Murders (1928) with a letter to Willam Roughead (also a crime writer), which has the tone of a dedication. Here he refers to his interest in murder being stirred in boyhood by the Borden case. Born in 1880 , 
young Edmund would have been twelve years old in that thrilling summer of 1892 , as Newburyport, Massachusetts buzzed with the news of the slaughter. But he went much further than most curious citizens, and seems to have become quite attached to Lizzie, or at least his idea of her. He calls her "that Lady of Fall River, toward whom you have expressed devotion." Pearson's devotion was no less. Toward the end of his life, he refers to her in a letter as "my beloved Lizzie" (Williams 269). This may simply be his characteristic irony at work. A cynic might say he has reason to love the woman who helped him win great popularity as an author, but I suspect there is more going on.

A fondness for Lizzie is not unusual among some avid students of the case. I have on occasion heard remarks such as "you've got to like the old girl" from people who certainly don't condone murder and do believe in her guilt. However, Pearson's zeal seems almost religious, and is fraught with contradictions. He frequently expresses indignation that Lizzie's defenders saw her as a victim and ignored the grievous wrong done to her parents. Convinced of her guilt, he argues persuasively that she got away with murder, and he does this repeatedly. By the same token, Pearson openly shows deep adriration for the very qualities that made the murders possible. To him the crime is unique because of the murderer's "iron courage" (Five Murders 287). He also makes reference to his "extraordinary audacity" 
(studies 28). These are not traits usually associated with pineteenth-century ladies, and in fact would seem more characteristic of men, and only "heroic" men at that. While admiration may at first seem inappropriate, Wendy Lesser reminds us that "an interest in murder crucially involves the admiration of craft", of both murderer and detectives (14).

Rather than fitting the image of a brilliant fiend, Lizzie was a thoroughly conventional lady who never publicly expressed any interest in being other than she was. She lived with her parents until their death, had no training or ambition for a career, and devoted herself to church activities. Feminism was as foreign to this life as flamboyant manifestations of "iron courage" and "extraordinary audacity." However, feminists did come to her defense, and Pearson refers to them disparagingly, often as "sob sisters." These women who were attacking the bastions of male power, with great courage that Pearson does not admire, were often accused of being unfeminine. They, unlike Lizzie, seem to make him nervous.

How much more attractive is Lizzie, who expresses no intention of usurping male power and generally increasing a man's anxiety. And yet, she committed the ultimate act of rebellion against patriarchy. Ann Jones has argued that society fears "both the feminist and the murderer," since they "test society's established boundaries" (14). Could 
Lizzie be less threatening because she refused to admit her guilt, and then quietly enjoyed her independence and wealth? I wouldn't think so; she remains a subversive character. Even if she makes one uneasy, there is much in the case which affirms dominant values and institutions. After all, the acquittal supports the power of the family and the notion of woman's moral superiority, if she is a lady. While Lizzie then becomes an heiress, she is also marginalized, rendered powerless.

It is this very marginalization that may have appeal for Pearson, who is drawn to the shadows. We see this tendency also in a work not about Lizzie, Queer Books, which consists of bibliographic essays on literary oddities such as temperance novels, Alonzo and Melissa, and truly bad poetry. Pearson enjoys drawing our attention to the odd and forgotten. When he decided to revive her story, Lizzie Borden could be described as both. It may have provided him with a satisfying sense of power and control, and to some extent, the reader can share this. Lizzie may have been very rich and reclusive, but her life, her character, her motives, are laid out for public consumption, amusement, and edification.

Pearson's attitude toward Lizzie is complex and not easily resolved. I suspect that his ambivalence, his horror and admiration, contribute to his success with readers. He presents us with more than a sensational murder story. 
serious moral and psychological questions are implicit here, not only regarding Lizzie but ourselves. Many believe that she did the unthinkable for prosaic, practical reasons, perhaps saving herself and Emma from a life of poverty if Andrew had been planning to change his will. Afterward, she never harmed a soul. Her story repels but also fascinates, touching perhaps what is usually repressed. It may be that the contradictions make it work. And contradictions in the sphere of popular culture are not all that unusual. Jim collins views culture as depending on "discourses which construct it in conflicting, often contradictory ways, according to the interests and values of those discourses as they struggle to legitimize themselves as privileged forms of representation" (xiii). What we see in Pearson reflects a tension between the discourses of true womanhood and the crime narrative, where a case is constructed, solved, and the vast legal system proceeds inexorably to convict and punish the evildoer, restoring the moral order. Both scholars (Betty Mitchell) and popular novelists (Evan Hunter) have shown how the ideology of true womanhood operated in Lizzie's favor. As the 19th century progressed, women were less likely to be convicted for murder:

"Favoritism toward women under the criminal law was the trade-off men made for stripping women of rights under the civil law" (Jones 98). Both these conflicting discourses affect Pearson and coexist uneasily in his texts. 
It should also be noted that not everyone accepted the dominant ideology of an essentially benign, gentle, or nurturing womanhood. Cesare Lombroso, founder of crimimal anthropology, viewed women as capable of crime, although for ideological reasons rooted in a long history of occidental misogyny. He and a few others saw "the female soul...festering with revenge, jealousy, and cruelty. Women harbored 'evil tendencies more numerous than men's,' though usually latent. Inside the normal woman lurked 'the innocuous semi-criminal,' rendered harmless for the most part by 'piety, maternity, want of passion, sexual coldness, by weakness and an undeveloped intelligence." "The traits of the female criminal included "an excessive desire for revenge, cunning, cruelty, love of dress, and untruthfulness" (Russett 73), all of which Pearson identifies in Lizzie. However, "in England and America very few men of science were willing to view women as 'Innocuous semi-criminals,' still less as 'born criminals'" (74), and he was not prepared to go that far either.

Let us look more closely now at Pearson's books. Studies in Murder is the first to feature Lizzie, and appeared during her lifetime. It was quite successful, published in July and reprinted in August, 1924. One cannot help but wonder if she ever saw it.

His self-imposed task is to revive an old murder case, and he does so with gusto. "Miss Borden's name means little 
today to those who do not remember the year of her trial" (68), giving the author an opportunity to shape and create meaning and memory for this group of readers. He sets the scene, provides insight into Fall River and the Bordens, and presents a step by step account of what happened on August 4, 1892. At first he seems to avoid taking a stand on the issue of guilt, but as he goes on to describe Lizzie and the trial, the objective tone fades and becomes ambiguous. He thinks she got an undue amount of sympathy. He thinks her manner "tended to arouse suspicion" (91). Nor does he overlook the roles gender and class play. For one of Lizzie's background to commit such brutal murders is "almost unknown to criminology." An axe murderer is usually a man or "woman of base antecedents" (32). The implication is that Lizzie is different from other women, and that she might well have done it. The faceless murderer showed "considerable cunning and extraordinary audacity" (28). When Pearson looks at her picture, he sees a "face and chin betokening strength of character" (51). He also finds her "rather eccentric" (39). These are all thoroughly subjective impressions, but take on the ring of authority in this serious account.

Then he quotes Hiram Harrington, her uncle. There was no love lost between the two. Lizzie is "not naturally emotional." "Emma is very quiet and unassuming," while Lizzie is "haughty and domineering with the stubborn will of 
her father." She is "deeply resentful," and wanted to live in a style reflecting Andrew's wealth, so there were "constant disputes" over money. She is "sulky," with a repellant disposition" but shone as a "brilliant conversationalist" (40-3). Besides displaying the venom that gives the lie to idealized notions of family, Hiram adds the melodramatic element of evil sister/good sister to the crime story. While his credibility is highly dubious, these remarks have strongly influenced her public image.

Pearson goes on to describe the inquest and trial in detail, drawing on Edwin Porter's book and newspaper accounts. He also goes beyond, to life after the trial, and cites the shoplifting episode reported in the papers in 1897. Then he describes Lizzie's current genteel circumstances at Maplecroft. This emphasizes the open-ended nature of the mystery, as there is still a chance that while the principals live, a solution is possible. Pearson ends with a list of unanswered questions about the case, closing with "Will the whole truth ever come out?" One senses that if it does, he will be the first to report it. He has quite successfully created an arena where the public's imagination, fascination with evil and money, and anticipation of new and exciting revelations can freely play. Pearson is creating a desire for information where none previously existed, and now he will proceed to feed it. Three years later, in Murder at smutty Nose and other 
Murders, he inserted a short chapter near the end titled "The Bordens: A Postscript." In it he refers to his earlier book and quotes from it, calling the Borden case "the most interesting, and perhaps the most puzzling murder which has occurred in this country" (291). This is a good example of an author training his audience to think in terms of an evolving legend. Looked at dispassionately, there is very little to support the claim that this crime was puzzling. He refers to the murderer's "courage, coolness, resolution, audacity, intellectual power" (292), which sounds more like praise than condemnation. Then he presents a short summary of the murders and case.

It seems that his primary purpose is to keep interest in the case alive, since he does not reveal any startling developments. Rather, he shares with readers evidence that interest in the case remains strong after 33 years, drawing them into the growing group of Borden fans. He cites the 1926 obituary of Mrs. Churchill, the Bordens' neighbor, and other articles about incidents involving people connected with the case (295). He also quotes from a 1913 article by Gertrude stevenson, which appeared in the Boston sunday Herald and Fall River Daily Globe. It depicts Lizzie as "an outcast...a social pariah," regarded with contempt even by those who initially supported her. Pearson disagrees, saying she is not a "complete recluse." We should keep in mind that she was still living as he wrote this. 
The words used here to describe her perpetuate the Initial impression created of Lizzle--"stolid, immobile, unemotional appearing woman," "large strong features," "determination," "firm-mouthed." One might think such a person capable of murder. But he assures us the picture is incomplete, because many puzzles remain, and "lie deep in that mysterious region, the human heart" (302). By ending on this note, he not only expresses an acceptable reason for popular interest in a murderer, but leaves the way open for sequels.

Sure enough, the following year, 1928, saw the publication of Five Murders: with a Final Note on the Borden Case, The note is in the form of a postscript titled, "The End of the Borden Case." The only new information is the news of Lizzie's death in June of 1927. Apart from his rather extravagant claim that she was "the strangest and most enigmatic person in America," he has nothing new to tell us. The point of this postscript seems to be that now "the case is forever closed; the chance that the whole truth will be known is utterly gone" (266).

Once again he rehashes the murders and repeats Hiram Harrington's unflattering characterization of Lizzie. Pearson is like a lover who can't bear to end the conversation but has nothing left to say. He meanders from the case to later events and back to the case. If he cannot say goodbye, he can at least immortalize his lady. So he 
tells a couple of anecdotes, both involving axes, neither credible, and refers to them as "legends." To show Lizzie's farflung fame, he tells of seeing the famous quatrain

printed in a newspaper in Durban, Natal:

Lizzie Borden took an axe

And gave her mother forty whacks.

When she saw what she had done,

She gave her father forty-one.

And he quotes two stanzas from Bixby's now obscure poem. Obviously we are expected to conclude that this is a notable woman. One should keep in mind that at this time Pearson's books are the only ones available on the case, and he probably feels the responsibility of perpetuating the story, as well as an interest in the financial benefits of selling many books. In a footnote, he mentions that the only book entirely on the case (by Porter) is out of print (291).

Many people familiar with the case have taken strong positions regarding Lizzie's guilt or innocence, and view it as a puzzle they have solved. But Pearson, who in no uncertain terms has repeatedly stated his belief in her guilt, is transforming this story. He claims "her character becomes a mystery" (291). He ends with a recreation of the murder scene, inviting the reader to participate--"Imagine a woman of sullen disposition..." and "make your choice" about her guilt (290-1). With help from Pearson, Lizzie moves into the realm of fantasy. 
contrary to the claim in his subtitle, this was not the final note on the case. More Studies in Murder (1936) contains a chapter titled "Legends of Lizzie," continuing what he started in the previous book. Edward Radin mentions that this essay first appeared in The New Yorker (171), providing Pearson with an even wider readership. Why can't he drop this overworked theme? Pearson's obsession, and that of future crime buffs, can be explained in part by the lack of closure in the case. Even though many believe Lizzie was the culprit, it is still officially an unsolved murder, and a final note is literally impossible.

It is quite evident that Pearson savors telling and retelling the story, even when nothing new develops from the exercise. This is a recurrent pattern. Many other authors over the years appear to take the same kind of pleasure in the narrative. I have also observed this when people get together to discuss the case. Even though they are visiting very familiar ground, they become absorbed and intense. There is much enjoyment in the repetition of this story. In this book, Pearson opens on a humorous note, stating that he considered leaving Lizzie out but gave it up because "of all the curious gallery of folk whose adventures I have Investigated, [she] seems to have the widest attraction." He claims that people still send him news of Lizzie "in song or story," and "her devotees are many and various." His purpose here is to pass along some of their stories. He 
also wants to share them because the "fictional" Lizzie is different from the "actual Lizzie Borden of history," (about whom precious little is known, though Pearson implies he knows her well). Since there was then a play staged starring Lillian Gish as Lizzie (Nine Pine street), he wants to focus on the "real" Lizzie. It looks like Pearson is noticing a shift in the creation of her character, and he is trying to maintain some control. He will set us straight, he will be the "standard of truth" against whom biographies must be measured, and he will also contribute to the mythicizing, as he freely admits that some of his stories are myths.

The "real" Lizzie is necessarily superficial. She was "plump and complacent," liked to cook, read sentimental novels, and visit art galleries, all qualities which many readers might share, making her "one of us." Yet most people in town "believe that this gentle lady chopped her stepmother's head to bits..." (No one can accuse our author of being understated.) A sinister note (rather a cheap shot) is introduced when he describes her as a schoolgirl, her "face rather heavy... a little menacing." We must remind ourselves that this is, according to Pearson, the "real" Lizzie, not the legend. It seems that they are merging here. She is like us, and yet she is not.

While he admits that some of the stories about her are preposterous, others are credible, most notably the one that 
has her sending Mr. Moody, one of the prosecutors, a package of photographs from the case, including the mutilated victims. Her accompanying note states that he might like them "as souvenirs of an interesting occasion."

Among the legends: Lizzie committed the murders in the nude to avoid staining her clothing. An invalid Lizzie visited in Fall River was found strangled. Before the murders, Lizzie wrote to friends about a nice, new axe. As a schoolgirl, she visited a friend who died overnight, which she calmly announced at breakfast. She stayed for the reading of the will, and accused the family of suppressing the true will which benefited her. Finally, after the trial, Lizzie visited friends on a farm. One pointed to a rotting old shed and said she'd have someone pull it down. Lizzie enthusiastically offered to do the job, and requested an axe.

These are of course silly, and Pearson knows it. But narrative enhancements and mythologizings serve several functions. They reward his faithful readers (clearly "fans"), who can feel that their interest in this case is justified; and they reinforce a group identity for students of the Borden case. They also attract new members of the fellowship. It should be emphasized that Pearson's style throughout is very humorous, and his light touch makes a grim story most enjoyable. The legends afford him an opportunity to entertain, and to perpetuate the image of 
this woman who has so long obsessed him.

His lifelong obsession ends with the final book, The Pal of Lizzie Borden, only because his life ends. I suspect that had he lived, he would have remained faithful. This book continues in the same witty style as the others, exemplified by his early announcement that the Borden family coat of arms shows "a Lion rampant, holding a Battle-Axe, proper." Victoria Lincoln uses this in her book as well, and acknowledges him and Porter as important sources. The humor which frequently marks Pearson's writing (and Lincoln's) is more than a pleasant stylistic feature, although as that it should not be underestimated in contributing to his appeal. In her feminist analysis of murder cases, Jones claims that women who murder are seldom taken seriously, and she cites Pearson's "amusing homicidal anecdotes" (xv). While she has a point, it is evident to me that Pearson was also quite serious about Lizzie. It is commonplace now to recognize that laughter enables us to face frightening situations, and gives us a sense of mastery. Victoria Lincoln, Evan Hunter, and Angela Carter enhance their texts with humor, while others, like Arnold Brown, attempt and fail, and it is not surprising that the now little-known poem by Mr. Bixby is so lighthearted. The legend is more palatable for the laughter.

Humor aside though, Pearson's intent here is also very serious, as the main part of this work is taken from the 
transcript of the trial. He also presents a slightly condensed version of Lizzie's inquest testimony, which is the only time she ever testified in the case. Some have accused him of using only the most incriminating extracts from the transcript.

The first part of the text introduces the trial by giving a detailed account of the family and the murders. He also supplies considerable information about Fall River. Pearson continued to believe that Lizzie was guilty. He dedicates this book to Hosea Knowlton, "a courageous public official," and the prosecutor in the case. A connoisseur of murder, Pearson offers the opinion that "many of the best murders are committed...for...avarice" (44), implying this was Lizzie's motive, a not uncommon theory. Although she was acquitted, he finds it a peculiarity of the case that "the verdict was never considered a satisfactory conclusion" (59). Statements like this are typical of Pearson. As it happens, a great many people in Fall River were quite satisfied, and wanted nothing more than to see the case sink into oblivion. The unsatisfied party is clearly Mr. Pearson who, convinced of her guilt, to the end paradoxically presents the case as an insoluble mystery. Like Lizzie, he gets away with it.

A hint of the old admiration for the skills of the murderer which we saw in his earlier books enters here, as he notes that the "deaths were shrewdly planned" (37). One 
wonders how he could possibly know this. Otherwise he is quite hostile to her defenders, the "two clerical busybodies" who engaged in "sectarian activity of a pernicious character" $(40)$, and especially to the women who took her part. They are "unintelligent feminists" (41) and "sob sisters." He holds back on insulting the more prominent ladies like Mrs. Mary Livermore, Mrs. Susan Fessenden and Miss Lucy Stone, merely calling them "militant," but this shows his discomfort with the gender issues raised by the trial. Women were not supposed to commit this kind of crime, and women were not supposed to be outspoken in defending other women, which is a task for men. This was a public arena, where female voices were unwelcome. The portrait of Lizzie which emerges here is sketchy. He sees a shrewd murderess, but otherwise must content himself with showing how very ordinary and respectable she appeared. He claims to have spoken with people who knew her, and none "had any explanation of her character, or pretended to knowledge of her inner life" (85). Thus, the aura of mystery is fostered.

Pearson's style is heavily ironic, extending even to his general descriptions of the men of New England. It contributes significantly to the readability of his texts. Irony is also peculiarly suited to the Borden case, since it presents us with a stunning example of the gap between what should be (dutiful daughter) and what is (parricide). This 
style was popular in Pearson's time, a period when "realistic and satiric reappraisal extended...to the lives and times of those formerly accepted as models for behavior of belief." Lytton Strachey's oueen Victoria (1921) is credited with ushering in this ironic new style (Hart 237). Pearson also has a disarming way of drawing the reader into the narrative. As he describes Andrew's final walk downtown, he invites us along--"today, you may follow his route as he went home" (3). He recreates key scenes in gory detail. And to reassure us that our interest is legitimate and not misplaced, he tells of others who are keen on the case, including Amy Lowell. According to an anecdote from a biography, she and other members of her distinguished family suddenly began to act out the Borden trial at dinner one evening (52). He also quotes the well-known rhyme, and tells us it "has gone round the world. I have seen it printed in newspapers from Australia and from Durban, Natal" (45). He even repeats a contemporary joke: "On the morning of the fatal 4th of August, someone asked Miss Lizzie the time of day. 'I don't know,' she replied, 'but I'll go ax Father'" (45).

To further give his text legitimacy and perhaps profundity, Pearson makes regular use of literary allusion. Alice Russell, a friend of the Borden sisters, is compared to Cassandra. Lizzie becomes Lady MacBeth--"all the perfumes of Arabia were not needed to sweeten that little 
hand" (90). The jurors contemplate the victims' skulls "like Hamlet in the churchyard" (93).

All these approaches can be seen as actually fashioning the reader, or at least implying an ideal reader. Whether the reader is a lawyer, a housewife, a secretary or a student, the model is one who has some education and will recognize those literary references. It is one who has an interest in "human nature," and human behavior, and enjoys playing armchair detective and juror. This is a rational, moral person who can contemplate a grisly crime but would never be involved in one. This person is sophisticated, with a sense of humor and a sense of justice. As the reader learns about Lizzie in these pages, (s)he is also receiving these subtle messages.

As a crime writer/biographer Pearson, for all his talent, also appears to have serious faults, the worst being his careless way with facts and uncritical use of sources, such as Porter, who was anything but a disinterested observer. Pearson presents his books as accounts of actual crimes, not as fictional works, yet he makes unsubstantiated statements, such as those about the murderer's "coolness, resolution...intellectual power." This is something he could not possibly know. In kore studies in Murder, he describes Lizzie as a "complacent" woman who "liked to go out with little-girl neighbors and feed the squirrels," and he makes it clear in a footnote that he refers to victoria 
Lincoln. Yet in her own book, Lincoln admits that Lizzie ignored her when she tried to strike up a conversation. Pearson was writing at a time when many of the principals in the case were still alive, providing rare opportunities for research. Even if some rebuffed him, others might well have talked. Instead, he relied far too heavily on Porter's book and the newspaper stories. Pearson was seemingly not interested in discovering new data; rather, he had constructed a version of Lizzie consisting of recycled bits and his own fancies.

If we hold him to to high standards of biographical facts and unbiased reporting, he falls short. But there are other considerations as well. If we think of biography as being constructed like a detective story, his faults are part of the technique. The detective story attempts to solve the murder in the face of skewed records and much unreliability in the appearances of the case, and all of these details are already coming from a particular cultural formation. We have victims, suspects, police and prosecutors playing out the drama. The standard formula enables "the audience to explore in fantasy the boundary between the permitted and the forbidden and to experience in a carefully controlled way the possibility of stepping across this boundary" (Cawelti 35). In 19th century America, "the focal point of conceptions of morality and social authority was the domestic circle." Actual accounts 
and stories of murders of relatives became extremely popular. In the $20 \mathrm{~s}$ and $30 \mathrm{~s}$, the gangster hero became a more popular form (77). Pearson's roots are in the 19th century, and it seems clear that there was still a residual interest in these domestic murders a few decades on.

Cawelti states that "the connection between the highly formalized and ordered character of the classical detective formula and its concentration on crime within the family circle can be seen....as a response to certain cultural tensions of the late 19 th and early 20th centuries." Social change provoked doubt and guilt. "For those committed to middle-class values of individual achievement and the ideal family, and yet dissatisfied by the restrictions of the family circle, the classical detective story offered a temporary release from doubt." It made crime seem "strictly a matter of individual motivations and thus reaffirmed the validity of the existing social order." Also, by making crime a puzzle, and using "a highly formalized set of literary conventions," a serious moral problem became "an entertaining pastime" (104-5). While Pearson's treatments of the Borden case are not classical detective stories, they partake of the characteristics of the form, and cawelti's observations throw considerable light on Pearson's handling of these narratives.

The genre that served him so well, the true crime story, also sets up certain expectations. For one thing, 
even though there was a chance that Lizzie was innocent, pearson could not pursue this point effectively unless there was another likely suspect he could focus on. There wasn't; it appeared that she must have done it, and he needs her to be guilty so that, in a practical sense, he has all the elements of his story.

Because the genre presents itself as non-fiction, the reader is led to expect an accurate account of the facts. As we survey the array of true crime/biographical writing about Lizzie Borden, it becomes evident that an untroubled representation of the woman and events as they actually were is an unrealizable ideal. It is possible to isolate some bare facts which no one disputes, but most of the material which renders this story so interesting is not unadorned truth but rather the result of intersecting personal concerns and social discourses. The question of truth here is a troubled one.

Not surprisingly, then, the picture Pearson leaves us with is somewhat conflicted. Lizzie is a coldblooded, brilliant killer, and a gentle spinster. He resents her; he adores her. She committed the murders; the murders are a profound mystery. She is a solidly respectable lady, thoroughly conventional and rather dull. She is utterly fascinating. He presents her to us in fragments, over the course of five books. By the end, we are no wiser about her, and no nearer to closure. This problem of binary 
presentation was also evident at the time of the trial. on the cover of Edward Radin's book is a quotation from the Mev York sun, June 5, 1893. Lizzie is referred to as "the most injured of innocents or the blackest of monsters." surely Pearson's study of Lizzie demonstrates the reductiveness and inadequacy of binary thinking. As readers of non-fiction, we expect to gain a firm idea of what Lizzie was like, yet she remains elusive. It would be silly to credit Pearson with a postmodern sensibility, but what emerges from his work is something like that. Rob Wilson neatly summarizes the major function of biography in the West as the production of "the myth of coherent personality." The subject's life is faithfully recorded by the biographer as a journey toward "coherent unity, striking personality, and expressive selfhood" (Epstein 167).

This is not what Pearson gives us. His Lizzie is a postmodern heroine, however unintentional. Still, there are a few coherent elements that stand out, and this is the stuff of legend. Bruce Rosenberg, in writing about heroes in history, observes that a group of "narrative elements...create a legend." It doesn't matter that most of the stories are inconceivable as history; what is important is that they are believed (84). The house on second street, the axe, the barn, the pear tree, the unemotional, pale-eyed daughter are all more compelling than the inconsistencies. 
And to further please his readers, Pearson offered Eychological puzzles, amusing narratives, and even the depths of human tragedy. Small wonder he kept the legend alive.

Edwin Porter's The Fall River Tragedy: A History of the Borden yurders was the first book published on the case, appearing in 1893. Although it has exercised considerable influence on the legend, few people had the opportunity to read it until recently. In his Foreward to the facsimile edition, publisher Robert A. Flynn explains that Lizzie bought out and destroyed most copies of the book. He does not indicate the source of this information, but victoria Lincoln says the same thing in her book. It seems a reasonable explanation for the scarcity of the book, which is rather hostile to Lizzie, until Mr. Flynn undertook to produce this edition in 1985. Both Edmund Pearson and Victoria Lincoln were able to hunt down rare copies, but the general reader had no access to it.

Porter makes much of his book's authoritative approach. The title page states his occupation, "Police Reporter of the Fall River Globe." He also includes a lengthy subtitle, "A Plain Statement of the Material Facts Pertaining to the Yost Famous Crime of the Century... Compiled From official Sources." In his Preface, he singles out this case as the most fascinating in American history, even after Lizzie's 
acquittal. He proposes to give the reading public a connected story of the whole case "from the day of the murders" to the end of the trial. He seems to be trying to impress with his objectivity--"her defense is given as freely as the case of the prosecution." It is as though he is responding to criticism he expects from her defenders that his book is one-sided. His newspaper's hostility to Lizzie was well-known.

This issue bears closer examination. The Borden case is not only about family and law in nineteenth century fall River; it is also about politics and class relations. Radin claims that the "bitterness" against Lizzie in Fall River is not the result of the murders but based on "caste... a small group against the many," marked by "long-festering resentment and frustration" (18). He accuses the Globe of being "one of the earliest practitioners of yellow Journalism in this country." While the elite in the town was Republican, the Globe was Democrat, and thus Lizzie's enemy $(20)$.

The reader, then, can expect biography in the form of chronicle or reportage, rather than a literary work. However, the distinctions are not that simple. We are not in some transcendant realm where only "facts" are linked to produce a narrative, with no room for dispute. Porter freely uses rhetorical and literary devices, and creates a picture of Lizzie which writers like Radin and David Kent 
consider unfairly selective and hostile. Porter does not hesitate to embellish the "facts." The opening lines of the book are hardly a plain account; rather, they are highly dramatic: "At high noon on Thursday the 4th day of August, 1892, the cry of murder swept through the city of Fall River like a typhoon on the smooth surface of an eastern sea." These murders were "so unprecedented," but he neglects to acknowledge that murder is not uncommon, even in families. By asserting the uniqueness and horror of these murders, "unparalleled monstrosity of the crime" (4), he contributes to the creation of a larger than life figure in the story, i.e. the accused daughter. Some of his heated prose does not even make sense, although it creates a fine effect. The killer "had wielded an axe...with the skill of a headsman." But wouldn't a skilled headsman have done the job in 1 or 2 neat, economical blows, rather than the repeated bashing the unfortunate victims suffered?

The sensational language intensifies--"a veil of deepest mystery closed around the scene." Because no clues were evident at the scene, he attributes brilliance to the killer--"no more cunning plan had ever been hatched in a madman's brain." It is interesting that he uses words associated with females (cunning, hatched). Porter also quotes Mr. John Beattie, an alderman who thinks the killer could have been a woman "cunning" enough to wear protective covering and burn it quickly in the kitchen stove. Our 
author ingenuously mentions this "simply...to show the trend of public opinion" (48-9). These are examples of the various rhetorical ways he implies his suspicion of Lizzie. The murderer "could not have proceeded more swiftly nor surely had he lived in the modest edifice for years" (6). In chapter 3, Porter describes the Borden family and gives a few details of Lizzie's background. "Her classmates say that she was rather eccentric in her manner of life, and of a retiring disposition" (23). He mentions her church work and membership in charitable organizations. Other references to her character are scattered throughout his narrative, and some are repeated for emphasis. Most notably, Porter presents Lizzie as a woman lacking the proper "natural" emotional makeup. He quotes a policeman who commented on her "remarkable nerve and self control" because she did not faint when she discovered Andrew's body (28). And when she was arrested, Lizzie "flashed a look at the Marshall, one of those queer glances which nobody has attempted to describe, except by saying that they are a part and parcel of Lizzie Borden." She was pale, but showed "little evidence of emotion in the almost stolid countenance." Then, to make sure we get the message, Porter refers to "her peculiarly unemotional nature," and adds, "though almost prostrated, she did not shed a tear" (65). He does concede that she broke into tears that night (66), and later, in the courtroom, was "not altogether 
memotional" (70). But even though a couple of instances of feminine emotion are recorded, they are overshadowed by the frequent emphasis on her unnatural coldblooded demeanor, obviously a murderer's trait. At the preliminary trial, Lizzie showed "that wonderful nerve" (82). And later at the trial, Porter finds her emotionless demeanor unfeminine (138). Porter was not alone in finding fault with her behavior. He quotes Mr. Knowlton, the prosecutor, who stated that the crime "was conceived in the head of a cunning, cool woman" (139), and that Lizzie was "nervy," "brave," and "cool" (296), "a woman whose courage surpassed that of any man I am talking to" (297). From this it is clear where Pearson got some of his key material and perhaps his obsessions.

Lizzie's extraordinary self-control has become part of the legend, and her defenders work hard to counter it. David Kent's recent book, Forty Whacks, published in 1992, purports to introduce new evidence in the case which clears Lizzie, but for the most part he is concerned with refuting the character assassination begun by Porter. Kent also claims to be impartial. He does not attempt a biography, but takes pains to explain Lizzie's manner, and in the process, provides his version of Lizzie. The rehabilitated Lizzie was a woman who did have friends after the trial. Ever kind and generous, she helped several students with college tuition, bought books for people, and was quietly 
charitable (209). Kent admits "a pronounced reserve of bearing and coolness of demeanor," attributing it to "inner shyness," and sees nothing abnormal. Rather, she had "a positive presence" (16). Furthermore, Kent claims that porter fabricated many of his stories about Lizzie, and that the Globe practiced "yellow journalism" (40). He says that she did show emotion at the funeral, albeit in a low key way (41-2), and elsewhere in his book provides other examples of emotional display. To prove Porter's bias, Kent cites news accounts of Lizzie fainting at the trial which Porter does not mention because it contradicts his "carefully crafted image of Lizzie" (98). The fact that so much is made of Lizzie's failure to conform to gender-correct behavior, a century ago and today, speaks volumes about our social practices and expectations.

To be fair to Porter, he quotes Lizzie's defense attorneys, who emphasized her spotless reputation, and church and charitable work (200-1). Mr. Robinson made much of her frank and direct answers to police, and her quick refusal to cast suspicion on Bridget, the housemaid, or John Morse (266). It is precisely this mixture of damning detail and impeccable character presented by Porter which so enchanted Pearson. Porter makes a point of relating an incident described by Mrs. Hannah Reagan, police matron, at the superior court trial. One afternoon, the women were passing the time in conversation. Mrs. Reagan said to 
Lizzie that "an egg could be broken one way and not another." When Lizzie tried and failed to break it her way, she said, "this was the first time she ever attempted to do anything and didn't succeed" (198). Surely such a woman would be capable of anything!

It is details like this in Porter's sly and selective portrait of Lizzie which remain with us to this day. David Kent tells us that two factors kept this case alive for so long. First, no further search was made for the killer, and second, every year, on the anniversary of the murders, the Globe ran a story hostile to Lizzie (210). These are Interesting and valid considerations, but surely there is more at stake here, and it is reflected in his dedication to the case. A most disturbing picture of a woman was constructed a century ago by our man on the scene, Edwin Porter, and we are still responding to it.

The fullest and most readable biography so far is Victoria Lincoln's A Private Disgrace; Lizzie Borden by Daylight. First published in 1967, when it won the Edgar Award for best fact crime book of the year, it continues to be widely available in a paperback edition. This edition contains excerpts from enthusiastic reviews in publications Including the New York Times and New Yorker. It is thus very likely that a great many readers in the last 25 years derived their picture of Lizzie from this book. 
Dterestingly, one of the reviewers quoted is Anthony Boucher (in the New York Times Book Review), who rejoices that the book "gives back to us our most beloved murderess." sside from echoing Pearson, his comment, while probably Ironic, also indicates an affectionate attitude toward the subject which has something to do with her status as a legendary figure in popular culture.

While I do not think that Lincoln presents Lizzie as a lovable individual, she is indeed humane in her approach. she is also a talented writer whose witty style and dry, ironic humor enhance the narrative. This may make Lizzie more appealing, simply because the reader is enjoying the text so much. Lincoln also provides psychological analyses of Lizzie's character and motives, likely to satisfy contemporary readers. This reflects the times, in that we take psychology for granted as a feature of biographical writing. Each construct of Lizzie that we examine shows the mark of the cultural concerns paramount at the time of its creation.

Iincoln opens her account by stating that "Lizzie Borden is an American legend," and goes on to claim that she will concentrate on the woman, not the legend (19). Her ability to do so stems from "first-hand knowledge," which will keep her text from sliding into fiction (20). It will be an act of "witnessing." Born and raised in Fall River, Lincoln was a member of the city's Yankee elite. She makes 
much of the fact that she and Lizzie shared the same world, though they were a generation apart. Lincoln's family lived near Naplecroft, Lizzie's house on the hill, and they knew the Bordens. This background provides her with more insights than an outsider would have, and allows her to place Lizzie in historical context.

However, despite Lincoln's authoritative tone and convincing claims to authenticity, one notes that she never knew Lizzie personally, though not for want of trying. As a child, the young victoria tried to strike up conversations when Miss Borden was out in her yard, but the lady ignored her. While Lincoln writes as though she knew Lizzie intimately, it is apparent that her imagination and narrative skills are masking a significant lack. Adding to this the fact that she used Porter and Pearson as sources, one begins to doubt the strength of the distinctions between Lizzie the woman and Lizzie the legend.

These considerations do not prevent her from providing a rich portrait of Fall River and the circumstances surrounding the case. She immediately sees the significance of having Mr. Almy and Mr. Milne among Andrew's pallbearers. They owned the Fall River Evening News and Herald, the establishment papers. These were, not surprisingly, very supportive of Lizzie, while the Globe, owned by Democrats, was not (140). Edwin Porter worked for the latter, of course. 
Another advantage that Lincoln claims is her gender. As a woman, and one not too far removed from the conditions Lizzie experienced, she interprets events differently from the male students of the case. Lizzie's burning of a dress, and the possibility that she was able to hide a bloodstained dress from investigators, are examined more closely and take on a damning concreteness. Lincoln's knowledge of feminine hygiene practices with regard to menstruation in those days also serves to build the case against Lizzie in a way that the men have neglected. According to Lincoln, the wellknown fact that Lizzie was menstruating at the time of the murders would have made it easier to conceal the weapon and bloody rags in her slop pail.

Lincoln is certain that Lizzie committed the murders, but she offers an interesting new theory about the events. First of all, from her abundant store of local knowledge she describes Lizzie's "peculiar spells" which only her acquaintances knew about. Many in this group believed that Lizzie killed while in the grip of a "spell" (24-5). After consulting a prominent physician at Johns Hopkins, Lincoln advances the theory that Lizzie suffered from epilepsy of the temporal lobe, and killed Abby during a fit (41-2). She had been wanting to poison Abby, but had been unsuccessful in obtaining the prussic acid. A pharmacist testified to her attempted purchase in court. A combination of physical factors (her spells, connected with the menstrual period) 
and a serious financial threat (the proposed transfer of Andrew's Swansea property), precipitated the crime (67). Thus, Abby was dispatched in this most awkward and hideous manner.

Andrew's death, on the other hand, had never been intended, and if the poison method had worked, he would have been safe. Lincoln emphasizes that while Lizzie deeply resented her stepmother, she dearly loved her father. She did not want to kill him, but realized that if he discovered Abby's mutilated body he would know all. Lizzie desperately needed to be loved, and she killed Andrew because she could not bear to lose his love. It is this which, Lincoln believes, moves Lizzie from ordinary crime "into the realm of Aeschylus" (97). It is fair to say that Lincoln is indulging in a bit of legend building here. Also, unlike the men writing about the case, she takes more interest in the emotional ramifications.

Her sketch of Lizzie, based as it is on personal observation and insider information as well as standard research, conveys a "real" woman. However, close examination reveals the novelist at work, emphasizing certain traits through repetition, and insisting on others which fit her "characterization" of Lizzie. For example, it is easy to accept that Lizzie liked to spend money and was very kind and generous to servants and tradesmen. This is common knowledge, and can be easily verified by people still 
in Fall River whose ancestors worked for or did business with her. But how could Lincoln know that Lizzie was "lost in fantasy" yet "strangely deficient in imagination" (300), or that she was "always tasteless" (265)? These qualities may explain Lizzie's remaining in Fall River in near solitary splendor after the trial, but there could be other explanations.

Rich in invention though it may be, Lincoln's text, liberally laced with observations, enables us to visualize Lizzie. In later years, Lincoln recalls her as being "tall, stocky, jowly, dressy, and unremarkable" (26). The latter point is significant, as others who remember Lizzie have indicated that she looked just like all the other old spinsters in town. Lizzie had curly hair, broad shoulders, and an "unfortunate" complexion, "coarse and sallow, it flushed to a mottled crimson" when she got excited (37). Iincoln mentions this again later in the text. Always fashionably dressed, Lizzie loved having her picture taken by professional photographers (37). Lincoln studies these portraits carefully, and notes a big difference in the photographs taken before and after the year of the murders. She concludes that both Lizzie's appearance and character had changed (266).

Only Lizzie's eyes never changed, and they seem to enthrall Lincoln. Over and over again she refers to Lizzie's "huge, protruding, pale eyes" (158), her 
"startlingly pale eyes" (199), eyes "hugely open" (301), Plank-eyed" (266), and so on. Lincoln remembers seeing Lizzie take her daily automobile ride, "sitting alone and staring straight before her" (310). On the one hand we have before us a completely ordinary woman who Lincoln insists is "so essentially uninteresting" (304). It should be noted that "the murder plots we remain most attracted to... are those which assume at least a partial identification with the murderer" (Lesser 51). Surely Lizzie's ordinariness makes her easy to identify with. On the other hand we are haunted by those large, pale, empty eyes. They set her apart, making her odd, sinister, memorable, enigmatic, a legend. This description is necessary for Lincoln's portrait of Lizzie, and shows her power as a storyteller. Radin looked at the same pictures of Lizzie, and concluded that she had "large expressive eyes" and was not the least bit sinister (44). In the shaping of a legend, it is clear which image carries more allure.

Although Lincoln finds Lizzie's character "baffling," a mystery (32), this does not stop her from describing her in considerable detail. Lizzie was known to be "thumpingly forthright" (25), "baldly honest" (52), capable of lying only "from grim necessity" (65), and the "world's worst liar" (82), which might explain her contradictory statements at the inquest. It doesn't explain her kleptomania, which received publicity in 1897 when she was accused of stealing 
two paintings on porcelain from the Tilden-Thurber store. Lincoln alludes to this problem of Lizzie's with some delicacy, saying just that "until her middle years, she did odd things" (305). According to her theory, this behavior and "spells" ceased once Lizzie reached the menopause. Lizzie was also stubborn (192), a "strong character" (230), and maintained a "distant" manner during the murder Investigations (124). This "familiar stony calm" was sometimes broken by emotional display during the trial. Her supporter, Reverend Buck, called her self-control "the calm of innocence" (218). Behind this exterior was a shy person who craved attention and feared being overlooked. Lazy about her duties at home where she rarely lifted a finger, Lizzie worked hard for charities, which afforded her social recognition (38). "Both timid and competitive," she "could be a charming, kindly benefactor, but she never learned the art of being a friendly equal" (37). This strikes me as one of Lincoln's more astute observations. She implies that this may be one reason Lizzie was shunned by her peers after the acquittal. They could overlook the murders, that "private disgrace" they all wanted to paper over since they couldn't adrit that one of their own was capable of such a deed. They could not forgive her pretentiously naming her new home on French Street "Maplecroft," and renaming herself Lisbeth (302). (She had been christened Lizzie.) One simply did not do such things. She apparently lacked the 
social skills to see this and successfully reintegrate herself into Fall River society.

Perhaps to compensate for this lack, Lizzie had an "almost pathological love for birds and animals" (58). Indeed, she was a jealous person (57) whose "need to be loved outstripped her ability to love." Lincoln claims that all who knew Lizzie remarked on this (95). Lizzie could "never cope with rebuff, even from a child" (39). In her later, lonely years Lizzie, who loved the theatre, struck up a close friendship with the actress Nance o'Neil. This prompted some in Fall River to suspect that Lizzie was a lesbian, but Lincoln doubts it. While Lizzie was sentimental to the point of being "sickening," she was "sexually immature," and incapable of carrying on a love affair with anyone (309).

For Lincoln, she was neither "important" nor "endearing" (97). While admitting that Lizzie was "justly proud of her handwriting," Lincoln finds it "bland, inhuman, and void of character" (126). In fact, she claims that Lizzie wrote "the dullest letters" and also accuses her of being "utterly uncommunicative" (301), a far cry from the brilliant conversationalist described by Hiram Harrington. Perhaps Lincoln still resents being ignored by the elderly Lizzie. It is more likely that she is building her case for Lizzie's ordinariness.

The "mechanical emptiness of her last years" was 
somewhat mitigated by friendship with Miss Helen Leighton, who was also a friend and occasional guest of Lincoln's mother. Miss Leighton, an "outsider" from Boston, believed in Lizzie's innocence, and was touched that Lizzie would often use the phrase "as Father always used to say." She felt that Lizzie truly missed Andrew (310). Lizzie certainly chose an unconventional way to join him. She was buried in the Borden plot in Oak Grove Cemetery, but had planned an odd funeral service. A few people were invited to the house, and then were told she had been buried privately the night before. Lizzie had insisted on black pallbearers. Then, Mrs. Turner was engaged to sing "My Ain countree," and "the startled mourners went home" (316). One can see why, after all her research and ample description, Lincoln can state that she failed to solve "the central mystery" of Lizzie. There is so much that remains unknowable; so many actions challenge explanation. When Lincoln attempts it, we sometimes find ourselves asking, how does she know this, and questioning her sweeping statements. Yet she has been successful in presenting a coherent if somewhat fictional portrait of Lizzie. She acknowledges that Lizzie's hatred on the fatal morning was pomprehensibly human" (310), and attempts to convey Lizzie's many human foibles. Most effectively, though, Iincoln registers an otherness, something inhuman, reflected in those pale, blank eyes staring into eternity. 
While the preceding three writers were the most mifluential, they were by no means the only ones propagating the legend. Over the last thirty years, numerous authors have provided additional dimensions to the story. Most reafirm the popular aspects of the legend, and some take surprising new directions.

One of these is Edward D. Radin, whose Lizzie Borden: the untold story (now out of print) enjoyed considerable popularity in the early 1960s. The 1961 volume of Book Review Digest cites reviews from popular magazines such as Atlantic, New Statesman, New Yorker, Spectator, and Saturday Review. Newspaper coverage includes New York Times, San Erancisco Chronicle, Soringfield Republican, and London Times. A paperback edition also appeared, bearing on the cover reference to its status as "the sensational nationwide bestseller."

Radin was a reporter with experience covering murder cases and trials, and he did a respectable amount of research here. He cites both Pearson and Porter, but gives the case a fresh slant. Although he begins with the legend, he attempts to get beyond it to the "real" story and the "real" Lizzie. The real story in a nutshell is that Bridget the maid committed the murders, and Radin takes great pains to prove it. This position requires a rebuttal of Pearson. In a chapter titled "The Case Against Pearson," he expresses admiration for the man whose books provided his own "early 
knowledge of the Borden case." However, his admiration does not include acceptance, and he accuses Pearson of distorting the official record of the trial to support his view of Lizzie's guilt.

Radin's analysis of Porter's motives has already been discussed. His refusal to accept the popular view of Lizzie's guilt as shaped by these two writers also forces Radin to revise her image. In a chapter titled "The Unknown Lizzie," he makes a point of separating fact from myth, and pursues this throughout the book. Not only did he study the inquest and trial transcripts, but he interviewed people who knew her, and even got hold of some of her letters, which nare in the possession of family friends, a few collectors, and the Fall River Historical Society" (245).

The portrait of Lizzie which emerges here is radically different from the legend. There is a classic example of binary thinking in the leap from "bad" Lizzie to "good" Lizzie. The unattractive spinster with the blank gaze becomes a pleasant looking, petite woman with "large expressive eyes" and lovely reddish hair who, in fact, resembled many New England women (44). The icy demeanor so criticized at the trial is simply emotional restraint learned from her father (27). The eccentric, sullen loner disappears. In her place is a "normal" woman who, according to Mr. James Kirby who knew her as a boy, was "friendly and had a wonderful sense of humor" (46). She was "intensely 
loyal and devoted to her friends" (52), and led a inventional social life. Judge Benjamin cook recalls, "I would see her at the larger functions the old families attended...she went out with young men before the murders" (48). And three years after the trial, romance may have beckoned. The Fall River News, which Radin finds credible, reported her pending engagement to a Swansea schoolteacher. Publicity erupted, and there was no further talk of engagement or marriage (225). There are other shifts of emphasis. Following the trial, she was not bitter; rather, many remember her kindness. While Andrew was notorious as a taker, Lizzie gave to her city, and Radin cites her record of community service to dispute the notion that she was greedy (49). She performed many quiet acts of charity. He also discovered that she "maintained cordial relations with her former teachers," and often gave them tickets for impecunious students to attend lectures and concerts. She also financed medical care for a former teacher's mother (51).

All traces of otherness are gone from this picture of Lizzie, a "nice girl...fun to be with...gentle girl" (14). Surely such a girl was incapable of the bloody slaughter that took place at second street. Radin concludes that the "Lizzie Borden legend is still growing" (242), and he has certainly done his part to modify it. Curiously, his vision of Lizzie has not taken root in the popular imagination. 
The good Lizzie should appeal, but the bad Lizzie exerts the stronger fascination.

The legend demands recognition even when revisions are attempted. Arnold Brown's recent work illustrates this. In Me Borden: The Legend, the Truth, the Final chapter, he also tries to prove her innocence. He emphasizes facts, which "make a mockery of the legend" (7). Brown cites newspapers, Pearson, and materials at the Historical Society to support his theory, much the same sources others used to arrive at very different positions. He also discovered some new sources, and the principals involved are all conveniently dead.

According to Brown, the murders were committed by Andrew's illegitimate son, William Borden, a mentally deficient and dangerous lunatic who talked to his hatchet: Bill again talked to his ever-present hatchet as if it were a third person in the cider house, as alive as Henry. As Bill sampled more applejack, more and more of what he said was directed to the hatchet, almost as if Henry were not in the shed. He told his hatchet of all the things his other friend, Henry, had learned and how he wished his hatchet could taste the applejack (292).

There is no evidence that Andrew had an illegitimate son. But according to Brown, he existed and Lizzie knew he was guilty, as did the men who ran Fall River. They conspired 
to cover it up, and persuaded Lizzie to stand trial, promising to protect her. Lizzie was "innocent of murder but guilty of greed" (324). She kept quiet, and the sisters Inherited Andrew's estate.

Brown does not focus on Lizzie's character, and the omission serves to support the popular image. He goes to somewhat ridiculous lengths to avoid the legend, but reinforces it when he emphasizes her greed. Clearly, the legend is what drew him to his bizarre line of research, and it is what he holds up to readers even as he denounces it. It is too early to know how this book will affect the popular view of Lizzie. I find it unconvincing, but have spoken with people who passionately believe it is correct. Brown is currently feuding with several prominent Borden fans who find his theory ludicrous. One of the odder(?) and perhaps telling aspects of his work is that in a conversation he was heard to refer to this book as "my novel." The boundaries between fiction and historical fact, always problematical in the Borden literature, are not just blurred here, they have disappeared.

Frank Spiering's book Lizzie also raises questions about the boundaries between genres. Unlike Brown, he does not make passionate claims to truth, but he does state that he solved the mystery, and presents the case in a fact-laced novelistic style. He recreates the murder and trial scenes, using trial transcripts, newspapers, interviews, and the 
books of Porter and Pearson, all familiar material. The novelty enters in his conclusion about the murderer's identity. Spiering argues that Emma sneaked into Fall River from Fairhaven, and killed her parents to prevent Andrew from signing over property to Abby. Lizzie knew about it, and took the rap. Hardly an innocent, she had earlier tried unsuccessfully to poison Abby. The motive, then, is the familiar one of greed.

spiering devotes little attention to Lizzie's character, describing her as attractive, unhappy, and lonely. She loved Andrew and was close to him, but, like Emma, loathed Abby. A new aspect of Lizzie emerges in his claim that she had a lesbian relationship with the actress Nance O'Neil. Clearly, Lizzie's sexual orientation has nothing to do with the murders, so the focus on it here seems largely the result of a cultural change. In 1984 , such matters could be openly discussed. (Victoria Lincoln in 1967 discreetly mentions it and quickly dismisses it.) The legend continues, with a new contemporary dimension. Robert Sullivan, unlike these revisionists, is convinced of Lizzie's guilt. As the title of his book, mobye Iizzie Borden, indicates, he wants to put the whole business to rest by issuing his definitive resolution. He speaks of the "enduring public obsession" with this sordid tale (210), and regards it all with great distaste, yet clearly is caught up in it himself. 
sullivan was a lawyer and later a judge of the ssachusetts Superior Court, and had experience with murder trials. His status is significant, since he brings the trappings and authority of a powerful institution to bear on the story. He states in his preface that he is basing the book on the trial transcript, and insists that he is taking a purely disinterested approach. Interestingly, this model of an unbiased judge which the legal system assures us is the norm, quickly proves illusory, and has wider implications for the study of the Borden case.

Although much of the book is indeed given over to explanation and analysis of the legal proceedings, there is also the extraordinary inclusion of "information" supplied by Mrs. Abby Potter, whom he interviewed in 1972. She was Abby Borden's niece, and had good reason to loathe Lizzie, who deprived her of her aunt and all hopes of sharing in the Borden wealth. He treats her version of events as the unblemished truth, and even goes so far as to repeat an absurd anecdote from Mrs. Potter. It seems that before the murders, Lizzie got annoyed with Abby's cat, and chopped its head off. This sounds like a story we might find in one of Pearson's books, not in a serious study by a judge.

Sullivan also provides some biographical details about Lizzie, even though his main purpose is legal analysis rather than character study. She was "no great beauty," had her "father's abrupt manner," was socially ambitlous but had 
no gift for friendship, and had a tense relationship with her stepmother (20-3). These are all familiar points presented by those dedicated to building a negative picture of Lizzie. After the acquittal, she is described as an Nunpleasant spinster" (205). And thus the legend is perpetuated.

A less scornful but very odd treatment of Lizzie emerges in Charles and Louise Samuels' The Girl in the House of Hate (1953). Now out of print, it appears to have had a limited distribution, and one could reasonably be amazed that any publisher would accept it. The one who did seems confused, as his note to the reader states: "It is our pleasure to keep available uncommon fiction...this title is printed in an edition limited to 300 copies."

Rather than being a fictional treatment of the case, the book consists mostly of the inquest and trial testimony, though the authors never properly cite their sources. They also quote Porter, Pearson, and Hiram Harrington. The authors occasionally interject their analysis, which can only be characterized as idiotic. The quoted testimony lends the text a serious tone which alters abruptly when they chime in. They constantly refer to the Borden residence as the "House of Hate," introducing a Rensationalistic, carnival tone. Further, they insist that when Lizzie murdered her parents, she was "unconsciously doing her bit to free her sex from its traditionally 
Inferior position." She "stunned the whole male sex out of its condescension toward women" because she killed "better" than a man and triumphed. They make the astonishing claim that "the old double standard started to disappear just about then," and attribute it to Lizzie. Furthermore, "if today woman has come out of the kitchen, she is only following Lizzie, who came out of it with a bloody ax and helped start the rights-for-women bandwagon rolling" (143). one wonders if this is a parody. Bizarre though their conclusion may be, especially for its time, I have heard people claim that Lizzie is a feminist heroine. No one has as yet satisfactorily explained how killing one's parents makes one a feminist.

The authors also state that Lizzie was "definitely a Lesbian type," though it is doubtful that she "ever actually had love relations with another woman" (9). They offer no further discussion or evidence. The rest of the character sketch is more conventional, repeating elements of the legend. Like her father, she had "a grasping nature" and a "complete belief in her own judgment." She was "arrogant," "domineering," and had few friends. Hers was a "baffling character" (8). Like so many others who claim to know the identity of the murderer, they call this case "the all-time classic american murder mystery" (9).

In 1980, two serious books appeared which present the case from a broader, historian's perspective. The editors 
1890 selve into the social and historical context of the case. By providing copious primary materials such as reprints of contemporary newspaper articles, both Mmpathetic and hostile to Lizzie, interviews with, and letters from people who knew her personally, Lizzie's inquest testimony, and the interview Emma gave in her old age, they encourage readers to draw their own conclusions. Here is an array of Lizzies. There is no attempt to present a coherent character: rather, we see some of the social and cultural currents running through the case. For example, they quote a contemporary physician who said the murderer must have been female, as "authorities" consider "hacking" a feminine trait, the action of a "woman who is unconscious of what she is doing" (47). This allows us to see how medical discourse constructs gender, and influences perceptions of crime. They also analyze the newspapers for deeper insights, concluding that the New York Times reports show how the lawyers used "social, ethnic, and sexual stereotypes and values...to influence the jurors" (135).

Among the biographical details are many familiar notes. She was "like her father in many ways, stubborn, determined, and Independent;" "she wanted money;" and there was much dissension in the family. The haunting eyes are duly noted. There were those who described her eyes as colorless and empty. Some would say expressionless" (11-12). The famous 
Interview with Hiram Harrington is also anthologized. We see a succession of texts replicating certain images, feeding the legend. However, the interviews with others who knew Lizzie show different qualities. Here is a cultured woman, warm and kind, who was quietly generous with her money. This image appears less frequently in the literature. It can't be because this information is so difficult to find; rather, I suspect it is because more writers prefer the villainous and monstrous Lizzie. This situation is not unique. From his study of the Custer legend, Bruce Rosenberg observes that "more than one traditional pattern, one legendary life, becomes attached to the man. Not everyone has the same idea of the hero, and so it is with Custer" (271). I might add, so it is with Lizzie.

In the second serious work of 1980 on Lizzie, Women who Kil1, Ann Jones takes a different approach. Her project encompasses much more than the Borden case, as she surveys the history of female homicide in the United States, from colonial days to the present. She devotes considerable attention to Lizzie, but is less interested in her personality than in the implications of her case, and the social and cultural dynamics involved. Jones believes that Iizzie was guilty, but that social conventions about the behavior of ladies saved her. She concludes that "it is no wonder that Lizzie became a legend to subsequent 
nerations, for her trial itself was the ritual reenactment of a very old legend: the embarrassingly trite tale of the damsel in distress" (235).

Another significant contribution Jones makes is placing the case in a broad historical context. Writers focusing on Lizzie often treat the case as unique, both in terms of the murderer and the horror and grisly details of the crime. But Jones shows that there were other sensational murders committed by women, for example, Belle Gunness (98). And the trial of Lucretia Chapman for poisoning her husband drew national attention in 1832 (87). However, these women did not become legends. Jones states that many of the women who committed murder had suffered severe domestic abuse. She does not pursue this line with Lizzie, as there is no record of abuse.

However, we note an interesting phenomenon in 1992, the centennial of the crime. In that year, four people independently of each other arrived at the theory that Lizzie was a victim of incest. A historian published an article in American Heritage, and a psychiatrist and two peychologists presented papers at a conference on the Borden Case, now printed in the proceedings. In her article, Marcia Carlisle starts with the legend of the greedy, fealous, socially ambitious younger daughter. She cites Sullivan and Jones, and recommends Porter, Pearson, Radin, and Lincoln. But she then re-views the scene with a 
Hstorian's eye, and makes the case for incest. She argues that "in the nineteenth century the connection between sexual abuse and homicide was simply not part of the public eonsciousness" (69). When victims did speak out about sexual abuse, they "were not believed or were labeled crazy" (72), and she cites cases. Now that silence is broken, and a new dimension added to the story. The three presenters at the conference make a similar argument, emphasizing the (opeculative) psychological aspects (evidence). They analyze the Borden literature, focusing on family relations and the many locks in the house. Dr. McNamara includes discussion of the legendary Lizzie's character. She was "withdrawn and socially maladroit," sullen, and a kleptomaniac, all characteristics of incest survivors. These writers are constructing a new narrative based on the old, popular one. While they argue convincingly, it should be noted that they base their proof on highly unstable sources. Another level is being added to the house of cards. This is not to imply denigration of this work.

Looking at this body of biographical writing, we can discern some interesting processes. If we think of these witers also as members of the audience, we see great variety. Recent studies of media audiences propose that the texts themselves may invite "oppositional, resistant readings that challenge the more hegemonic codes of popular culture" (Douglas 130). It has long been accepted that 
people kill because of greed, but until recently it was unthinkable that a proper victorian woman might kill because of incest. The women looking at the case tend to see it differently from the men. Some refuse to see the murderer as a "bad guy," and try to revise the character. Others want to be sure she was truly wicked. The fragmented, itinerant desires of audiences "produce" the critics and narratives as their own object of desire. We see the reworking of historical material into symptomatic data of the genuine concerns and fantasies of daily life.

The legend is not fixed; it absorbs and accomodates changing social perceptions. A dialogic process is at work, each writer responding to and reinforcing what has already been written, responding to prominent discourses at the time of writing, and responding to and anticipating the imagined reactions of readers. The process coincides with Bakhtin's vision of a world where the contexts of dialogue are endless, and meanings change as perspectives and language shift. 
CHAPTER THREE

MEDIA FRENZY: LIZZIE AND THE PRESS

Lizzie Borden would not have become a legend if she had not become a media "personality" first. People all over the country could and did read about her in their newspapers in 1892 and 1893. She was even featured in a story in The Police Gazette, a popular magazine of the 1890 s (Kent Sourcebook 220). To illustrate the impact of the case, one writer points out that "the New York Times informed its readers that controversy over Lizzie Borden's innocence or guilt was directly responsible for 1900 divorces" ("Bordenmania"). Writing in 1943, William Emery, who covered her trial for the New Bedford Evening Journal, looks back with fond nostalgia, certain that "news coverage of this famous and sensational event was a marvel of the age, that has never been improved upon" (Kent Sourcebook 324-5). I strongly suspect that if Lizzie had been tried with little fanfare, she would be all but forgotten now. Instead, she became a household word, and even when interest in her abated and reporters moved on to new stories, the newspapers provided a rich archive for those who wanted to study the case further and publish their theories.

Examining news coverage of the Borden murders and trial would seem a straightforward exercise, but complex issues 
arise. Representations of Lizzie cannot be isolated from the social and economic forces which influenced the form they took. studying Lizzie in the papers reveals more about the society in which she lived than it does about her. Most of the articles I read, besides the New York Times, appear in a book compiled by David Kent, who drew on clippings from forty-three newspapers, and can be said to be fairly hepresentative of the coverage in the press. One quickly sees certain trends in the approach to Lizzie, and they are based on her gender and on the social concerns and obsessions which predominated in 1890 s America.

It was Lizzie Borden's misfortune that she lived during a time of dramatic expansion. In the years between 1870 and 1900, the high birthrate and heavy immigration doubled the population of the United States to seventy-five million. This affected the growth of daily newspapers, which increased sixfold, from 387 to 2,326. Subscribers increased wroportionately, from 3.5 million to 15 million circulation (Kobre 349-50). The growth of cities, their population, literacy, and needs were all linked to changes in American journalism (Baldasty 48-9). "News was a manufactured product in the nineteenth century...reflecting the financial requirements of the newspaper organization, the vision of its producers, and the day-to-day exigencies of production." There was a marked shift from politics to consumerism in the papers' economic base ( 8 ). This was the environment in 
which Lizzie Borden was presented to readers. Her notoriety, her image, were urban phenomena. In fact, the first report of the crime, in the Eall River Herald, does not target her but reflects the anxiety of the Yankee stablishment about expanded immigration. The headine refers to "a drunken farm hand," a Portuguese, as the suspect (Kent Sourcebook 1). Obviously, they prefer to think a "foreigner" committed the atrocious deed, rather than one of their own. The Boston Advertiser does report that the family is under suspicion, but adds that some "suspicious persons" were arrested but not suspected. Two Russian Jews passing through town and a Portuguese were "locked up simply by way of precaution" (4).

From day one the events in Fall River seem ideal news stories. However, news does not have a timeless, transcendent essence. In the late nineteenth century, "publishers and editors shaped and packaged the news to increase its marketability, and in so doing they emphasized content that was interesting, entertaining, and diverting." News not only reported the events of the day; it was "a selected account chosen for its ability to please both advertisers and readers" (Baldasty 113).

The Fall River murders met these criteria. What could be more interesting, entertaining, and diverting than the possibility that a respectable young woman had hacked her parents to death with an axe? It was a sensational crime 
replete with lurid, gruesome details which the respectable newspapers duly reported, with no need to embellish for effect. We can read full descriptions of the wounds, of the victims' heads being removed for autopsy, and bodies being buried without heads. The New York Times, for example, on June 14, describes Andrew's skull brought into court, and a witness demonstrating how a blow was struck, using a lawyer to stand in for the victim, as "a shudder went over the courtroom." It is all the stuff of nightmares.

sensationalism, however, is not only a feature of nineteenth century journalism. It has a long history. Mitchell stephens traces it back to colonial days in america, and even further back in Europe, in publications that preceded newspapers, and even back to ancient Rome. He considers sensationalism to be "rooted somehow in the nature of news," since most news... is intended, in part, to arouse, to excite, often--whether the subject is a political scandal or a double murder--to shock" (1-2). A glance at papers of the 1890 s shows there were many murders though, and most did not get the same level of attention as the Borden case. There was another murder in Fall River at the same time, for example, the Bertha Manchester case. Stephens finds that "the crimes that have most intrigued the readers of modern American newspapers" seem to have four characteristics in common "beyond mere heinousness"--"a woman or child as victim or suspect; a highborn or well-known victim or 
suspect; some doubt about the guilt of the suspect; and intimations of promiscuous behavior by the victim or suspect." Famous twentieth century crimes have at least three of these qualities (108). Interestingly, the Borden case has the first three, and attempts were made to include the last, in the infamous Trickey-McHenry affair.

This was a hoax involving the Boston Globe. In october, 1892, the paper printed a story about new evidence in the Borden case. Supposedly, witnesses standing outside the house on second street on the night of August 3 heard arguments between Lizzie and Andrew about a lover. Others were present outside the house during the murders, heard screams, saw Lizzie wearing a hood, and other startling sights. The source of these thrilling developments, a detective named McHenry, even claimed he sneaked into the prison and hid under Lizzie's bed to eavesdrop. He sold these highly dubious stories to the Globe reporter assigned to the case, a man rejoicing in the name Henry Trickey. The Globe printed these revelations on its front page, clearly without checking them, though it claimed to have done so. of course it caused a furor, sold many papers, and was highly profitable. Soon thereafter, the paper was forced to print an apology, as the "evidence" was a complete fabrication (Kent sourcebook 315-9).

While it might be tempting to dismiss Mr. Trickey as a bungling idiot, it would not be entirely fair. We need to 
take into account the economies of the news business. At this time in history, newspapers saw their costs rising significantly. "Efforts to contain costs substantively influenced news gathering and processing. For reporters, space pay, job insecurity, and long working hours tilted news away from a faithful representation of events." Often the results were fabrication and exaggeration (Baldasty 145). Some of these factors may well have influenced Trickey and his editor. At any rate, this bit of unethical fournalism seems to have done no harm to Lizzie. In her analysis of the Trickey-McHenry affair, Victoria Lincoln thinks it may have helped Lizzie, since it "proved, once and for all, what kind of people were against her" (222-3). In this case, it is clear that outright fiction was reported as fact. But facts can be slippery, as Gaye Tuchman explains. The word "fact" did not have the same meaning in 1848, "when the first American wire service was founded," as it did in 1865, 1890 or 1925. "For the early wire services, presenting facts connoted presenting Information acceptable to the editorial policies of all newspapers subscribing to the service" (159). And in reports on the Borden case, one can also question many of the "facts." When the Fall River Herald states that "hardly a person in the city does not pity her" after Lizzie's arrest (Kent Sourcebook 114), one wonders if the editor's support of Lizzie has anything to do with this perception. 
It is useful to keep in mind that factual reporting moorporates cultural tropes, so it is not surprising to encounter elements of the horror story, reverence for virtuous womanhood, the sacredness of the domestic sphere, and fears of contaminating it. A woman writing for the Poston Herald, August 6, describes Lizzie as having "a wealth of black hair" and "dark, lustrous eyes" (14-5). Whoever she was looking at, it certainly was not Lizzie Borden but a romanticized heroine. This may have made good copy and given readers a reassuringly familiar image, but it raises doubts about the reliability of the information presented.

The fact that this reporter was emphasizing the woman's point of view in her piece raises another significant issue, that of women readers. By this time, women were a "key demographic target" for advertisers, since they managed households and spent a good deal of money. Some newspaper content was aimed directly at them (Baldasty 117), as this article illustrates. The reporter interviews Lizzie's friends, who have only the highest praise for her. They laud her "church work, her modesty of manner, unswerving sincerity, gentle forbearance and aspirations to be and do all that is best and right in life." Lizzie has "dignity and reserve," "a sensitive nature," and was so shy she did not have friends until she became involved in church work. Another example of targeting women is the piece by Mrs. 
Percy, correspondent for the New York Herald, printed in the 11. River Herald. She describes her tour of the Borden house, providing many details sure to interest the ladies (Kent sourcebook 145). Actually, these would seem to be of equal interest to many male readers as well. It strikes me that these articles are not so different from those written by men, of whom there were far more reporting on the murders and trial. The personal details about Lizzie are described in similar terms and style. Interest in this case cut across gender lines, and women were certainly fascinated. This wide appeal must have delighted advertisers. Perusal of the New York Times daily coverage of the trial, for example, reveals ads on those pages for a variety of products, including household items, clothing, and medicines.

Much is made of Lizzie's appearance. Reporting on the inquest, the Fall River Herald states, "in the past few days Lizzie has terribly aged. The full round cheeks that friends of her former days remember have entirely disappeared, although the bright eyes and haughty expression are still retained." "From her every movement the woman would be the last person to suspect of the crime" (38). At the trial, the Boston Daily Globe described her as a "very plain-looking old maid," and gave a detailed account of her dress. Though she looks careworn, she is "no Medusa or Gorgon... nothing wicked, criminal, or hard in her features" 
(206). The New York Herald finds her a "masculine looking woman," whose "voice has a peculiar guttural harshness" (32). The journalist Joe Howard gives his impression on the first day of her trial: "her wide-apart eyes had an unpleasant stare," "her cheeks, which are over full, hang down below the line of the chin" which is "obstinate and stubborn" (202-4). The New York Times (June 6) observed that she "looked unusually well" in her "black brocade dress and a black lace hat."

This objectification of women has long been present in our culture. Although Lizzie is on trial because of something she did, because she was an agent, albeit breaking the law, she becomes an object of our collective gaze. John Berger observes, "men act and women appear. Men look at women. Women watch themselves being looked at. This determines not only most relations between men and women but also the relation of women to themselves." The woman "turns herself into an object--and most particularly an object of vision: a sight" (47).

Even more is made of Lizzie's demeanor and conformity or lack thereof to standards of feminine behavior. It seems that when she conformed, there was approval, and her actions were a sign of innocence. When she did not, she became disturbing, moving to the realm of "other." In these terms, Lizzie did well at the funeral, according to the New York Times, where "her nerves were completely unstrung, as was 
shown by the trembling of her body" (16). Four days after the murders, the Fall River Herald quotes Pinkerton detective Hanscom, who thought "the murder looked like the work of a lunatic, while Lizzie appeared to be a levelheaded, self-possessed woman." However, she was giving way wunder the great strain and excitement of the last four days," and was under a doctor's care (22-3).

Despite these occasional signs of female weakness, everyone seems obsessed with her stoicism. It can be clearly seen in a review of the trial coverage in the New York Times. Considered to be our newspaper of record, its fortunes were not always the best, and it was in trouble in those years. Profits were shrinking, equipment getting old, and "the panic of 1893 hit the paper hard." Circulation was falling (Kobre 402). The paper did not send a reporter to New Bedford; rather, it used dispatches of the Associated Press and probably other sources among the reporters on the scene (Kent Sourcebook 324). Kent, an impassioned defender of Lizzie, gives the paper high marks for unbiased coverage. As one might expect, the daily reports present much Information about the court proceedings, but also show enormous interest in Lizzie's demeanor. All that is missing is a chart showing her low and high points as the trial progresses. A brief chronological list illustrates my point:

June 6: "as self-possessed as ever" 
June 7: "as calm and unmoved as ever" but then she shocks everyone by fainting.

June 8: "the weakness of yesterday had vanished," with her "strong will" returned.

June 11: "calm and self-possessed"

June 13: "showed signs of great agitation" and wept during description of victims' wounds.

June 15: "unusually cheerful"

June 17: question was asked if she shed tears when viewing father's body, and answer was yes.

June 21: waiting for verdict, her "self-possession never deserted her, but her face became livid, her lips were compressed, and her eyes assumed a vacant look." Hearing verdict, she "wept such tears as she had not shed for months."

On the first day of the trial, the paper also ran a background article on the crime she was accused of, "one of the most remarkable in the long calendar of mysterious murders...during the past fifteen years." Authorities fixed on Lizzie "because she had appeared so calm and composed on the day of the murder" and because police thought one of her gowns had blood spots on it. An interesting complication marks the reporting scenario. The press is caught between two types of gender bias. Because she is a woman, there must be attention to her looks and femininity. Any hint of hysteria or emotion, or deviation from conventional 
responses must be noted. But she is accused of two grisly murders, and the ruthless binary formula of horror requires Indirect masculinization (looks and behavior) of the culprit. These perspectives coexist uneasily in the stories of the reporters.

The correspondent for the Boston Herald refers to her as "the Puritan maiden" who steeled herself against adversity, but broke down when Mr. Jennings, one of her lawyers, spoke eloquently and kindly about her life and zeputation. "He championed her cause with an ancient knight's consideration for her sex and herself" (287-8). This reporter is quite insightful, finding a reasonable explanation for Lizzie's behavior in two old and familiar narratives. Her gender and social position indeed cast her as a damsel in distress, and that is what observers wanted to see. After the verdict, a New York Times (June 21) editorial calls her a "most unfortunately and cruelly persecuted woman" victimized by the "inept and stupid and muddle-headed" police in Fall River.

Another gender-based analysis comes from Anna Katherine Green, a popular detective story writer of the time. In a piece she wrote for the New York World she calls it "the crime of the generation as regards mystery and the shock it gives." She believes Lizzie is innocent, and bases this on gender stereotypes. The ferocity of the crime was "not consonant" with the behavior expected from a woman of 
Lizzie's background (138-9).

Aside from Lizzie's emotional state, reporters probed other aspects of her personality, not only during the "main events" but long after, when she retired from public view. kurder gives license to do a remarkable amount of snooping into people's lives, and nineteenth and twentieth-century reporting draws from a hoary and popular tradition. stephens describes seventeenth century newsbooks which contain many accounts of murder in families. They "offer glimpses of the most emotional aspects of ordinary life, aspects that would not otherwise have been made public." Then and now, "the commission of a crime justifies fascinating violations of privacy" (111-2). In the Borden case, the results of the reporters' interviews and Investigations are interesting and somewhat contradictory. Lizzie's family paints a consistently unflattering picture of her. Soon after the murders, the New York Herald quotes her uncle John Morse, who states Lizzie "was a peculiar girl, often given to fits of sullenness." The article goes on to claim that she "has been odd all her life," though "she has her defenders, who say she has an amiable disposition. The allegations to the contrary may be mere ill natured gossip" (Kent sourcebook 31-2).

The harshest words come from her uncle Hiram Earrington, who was married to Andrew's only sister. The Interview he gave, which was circulated widely and is 
mentioned here in a previous chapter, was devastating and provided fodder for Lizzie's enemies. The woman he describes is surly, greedy, ambitious, and combative (27-8): Lizzie...was haughty and domineering with the stubborn will of her father and bound to contest for her rights....Lizzie is of a repellant disposition, and after an unsuccessful passage with her father would become sulky and refuse to speak to him for days at a time. She moved in the best society in Fall River....thought she ought to entertain as others did....Her father's constant refusal to allow her to entertain lavishly angered her. I have heard many bitter things she has said of her father.

Two of Lizzie's Morse cousins also spoke to the press. Henrietta defended her innocence, but acknowledged that "Lizzie had always been a peculiar woman" (48). Even Emma Borden agreed. Totally loyal to Lizzie during her ordeal, Emma was a quiet and retiring woman who shunned publicity and refused interviews. In 1913 she broke her long silence. She reiterated her belief in Lizzie's innocence, but added that "Lizzie is queer," though certainly not capable of murder (337).

In contrast to her relatives' views, Lizzie's friends thought her a paragon of womanhood. This is evident in the gushing article by the woman reporter, discussed earlier. 
perhaps more importantly, faithful friends took the stand and testified in court about her excellent character. Admirers from far and near showered her daily with floral tributes which she brought to the courtroom.

In later years, the actress Nance o'Neil spoke to a reporter about her friendship with Lizzie. Nance seems to have been the reason Emma broke with Lizzie and moved out of their French Street home. In 1905, the Boston Sunday Herald announced "Lizzie Borden Left by Sister." The two quarreled over Lizzie's association with theatre people, which Emma could not countenance. It was rumored that Lizzie was writing a play for Nance, and "has literary ability, and has passed much of her time in reading, writing, and traveling" (329). Nance denied all unpleasantness, recalling her friend as a "reserved little gentlewoman" with gray eyes, and very different from the "unemotional, grim, stocky" figure in the public imagination. Lizzie was refined and intelligent, well-read and travelled, and spoke well. She was also "utterly lonely" (345).

Another friend, Helen Leighton, who was close to Lizzie and a beneficiary in her will, spoke about her shortly after Lizzie died in 1927. She evokes a woman who "could not bear to see suffering," was devoted to the welfare of animals, and helped many needy people. Lizzie was "bitterly unhappy" and suffered "days of most terrible depression," finding small pleasures in her love of theatre and reading. After 
being shunned by her congregation she stopped attending church, but had "at least a dozen devoted friends," to whom she was very generous (340). And so even Lizzie's death did not stop reporters from searching for keys to her personality. When her will was made public, it was covered extensively, and it was revealed that she was most generous to the Animal Rescue League, relatives, friends, and servants.

Mysterious as she was, the bottom line is she was interesting and helped sell newspapers, whose writers were not above encouraging the public's fascination. Joe Howard writes from New Bedford in 1893, "the interest in this case grows daily" (212). A New York Times editorial on June 17 announces that "it is many a year since a criminal case in this country has excited such universal interest and been the subject of so much discussion." Lizzie Borden and her ordeal were enormously entertaining, and a talented fournalist could work magic with such material.

Joe Howard "styled himself as the first syndicated columnist, and his reports... were read by thousands of subscribers of a dozen big city newspapers" (201), including the Boston Globe and papers in New York and the east coast (323). A seasoned journalist, he had been a Civil War correspondent at the battle front (326), and seemed to be having a jolly time at the trial in New Bedford. His pieces are written in a chatty, epistolary style, and signed with 
his surname. They supply extensive information about this most serious trial, but they also entertain with their witty, good-natured observations of the courthouse cow, loudly mooing outside the window and competing with the business indoors. He notes the "snores of weary yokels" in the audience (212), and describes with relish the sartorial splendor of some of the prominent men. "This has been an odd trial in respect to the raiment novelties being sprung upon the spectators day after day," including the Chief Justice's new stovepipe hat and Governor Robinson's new trousers (292). His irreverence is refreshing and one can imagine people reading his columns daily even if they did not care much about the outcome of the trial. It is also a visible reminder that this is about more than simply news. It is entertainment as well. It also makes a reader feel rather well-disposed toward Lizzie. On June 12 he writes that "although she had had two nights" rest and six square meals since the adjournment and had devoured with zealous interest chapter after chapter from the facile pen of the poor man's novelist, Charles Dickens, she was not in good form" (264). He could be serious and insightful in his accounts, too, and was moved by the same gender-related expectations as his colleagues. He found Lizzie "a most remarkable woman" because of her self-control, and was struck by her "unique and peculiar personality" (202-4). Cenerally sympathetic to her, on the day of acquittal he 
observes, "she is not an ordinary woman; she is a puzzle [ychologic" (307).

To Joe Howard she is a puzzle; to the indignant author of the New York Times editorial she is an innocent, "cruelly persecuted woman." Every journalist writing on this case has a hand in constructing Lizzie Borden for readers. puestioning the representation of news is something scholars have done for some time. Critics like Tuchman have long held that "the act of making news is an act of constructing reality itself rather than a picture of reality" (12). She points out that contemporary "newsworkers find it difficult to distinguish between fact and interpretation" (99), and this can be said of the reporters in the 1890 s as well. Additionally, "through its routine practices and claims of news professionals to arbitrate knowledge and to present factual accounts, news legitimates the status quon (14). We see this played out in the Borden case. Even though there were some complaints about the police investigation and the conduct of the initial court hearings, they were treated by the press as the orderly, proper actions to take in the face of the chaos that the murders introduced into the life of the town. It was simply taken for granted. In a June 20 editorial, the New York Times praises the trial as "a model proceeding from the opening day," which was conducted ably and expeditiously and kept within the limits of the proper dignity of a judicial proceeding." The 
conduct of the trial reaffirmed the validity of the American system of justice. The focus on gender reinforced dominant social values. The crowning touch was Lizzie's acquittal, in itself a bow to the status quo. It gave editors everywhere, except for a few mavericks, the opportunity to aymathize with Lizzie and salute the system which freed ner.

A review of the prodigious writing generated by so many fournalists shows several distinct narrative threads running through it. There is the story of the genteel, rich, virtuous young woman with an unblemished reputation accused of hideous murders based on circumstantial evidence. This is the woman who is rightly acquitted. There is the story of an unhappy, socially ambitious daughter of a miser who wants to live like her cousins on the hill. The home is filled with strife and hatred and locked doors. The daughter is known to be odd and moody. This is the woman immortalized in the rhyme; she has become a legend. There is the damsel in distress; there is the stalwart New England Puritan who faces hardship with a stony strength. There is the cultivated, kind, fun Lizzie; there is the nasty, bad Lizzie. There is the ice maiden who confronts us with a blank stare; there is the tender woman who weeps and hides her face behind a fan. Why does one of these achieve primacy and emerge as the indelible image residing in popular culture? There are probably many reasons, all 
impossible to prove. It may come down to a tension between prception and imagination. We read the newspapers and form an 1mpression. In 1893, it was predominantly favorable, and she was showered with sympathy, but this began to change fairly rapidly. We know that her person was immaculate minutes after her father's murder, and the weapon was never found. Perception dictates one image, but imagination another, and so she remains forever the lady who took an axe and gave her parents all those whacks. It might also be that the very presence of the incongruencies in the picture of Lizzie influenced the adoption of the familiar iconic figure. She just was not shown consistently as the wronged romantic heroine. In the arena of popular culture, institutions such as the press play a leading role, usually dedicated to preserving the status quo. The press tried in the Borden case, but was unsuccessful in maintaining the desired effect. The consumers of popular culture do not just passively accept an image; they sometimes resist and sometimes create as well, and we see the results to this day. 


\begin{abstract}
CHAPTER FOUR
LOOKING AT THE MANY FACES OF LIZZIE:

TEXTUAL FABULATIONS AND SPECULATIONS
\end{abstract}

It should be evident by now that the distinction between factual and fictional works is not always clear-cut, as many of the preceding "non-fiction" books and the purnalistic literature show a range of license and creativity. They demonstrate that questions of "truth" and the operations of language and culture are not just philosophic issues for academics to ponder, but a part of everyday life to concern all readers. In this chapter the problem will not arise in quite the same way, as I will explore the intentionally creative literature about Lizzie, in the form of novels, stories, poems, plays, and film. Many of these writers relied on the biographical/historical texts, as one might expect, and traces of these appear in their work.

The representations of Lizzie vary widely, as does the quality of the texts. In some she emerges as a simple, onedimensional character, while in others she has depth and complexity. Some writers are interested in retelling the story, some weave it into a larger plot, and others are more taken with the implications of the case. A range of Neological positions underlies these works, from the 
peservation of the status quo (Bierstadt, Lowndes), to feminisms (Carter, Hunter, Pollock), and the critique of capitalism (Carter).

some of these texts have attracted the attention of academics, and others are perhaps too obscure or lowbrow to interest anyone but a Borden fan. I find it fascinating that Lizzie has inspired such a literary output, ranging from kitsch to works consciously invoking the aura of "art." Distinguishing between these two poles can be problematic. Jerry Palmer observes that our culture does draw a boundary between "high" and "low" art. "High" art "defines itself as such by refusing the forms of ready comprehensibility and accessibility that characterise "low art'." While high art refuses access and commodification, it eventually "becomes both familiar and commodified anyway." Thus, "no permanent boundary" exists between the two, "but a series of evershifting, negotiable limits" (Potboilers 110). From this perspective, the aesthetic value of the Lizzie literature is of secondary consideration. Whether assuming high or low forms, this particular literature is interesting in terms of how it variously represents lizzie and also negotiates the boundaries and slippages of art, popular culture, and criminal transgression.

One feature common to most of the texts must be noted. In one way or another, they make a point of presenting the murders as an act of passion, a point on which the 
torical/biographical texts are silent. The latter show us a Lizzie known to be outspoken, but stoically calm in public. These artists, however, focus on passion and thus on the priority of "character." Agnes de Mille articulated one reason in her delightful book which describes both the Borden case and her work in transforming it into a ballet. She writes, "murder for real estate is not possible to dancen $^{n}(138)$. Passion is necessary as well. Others may have been influenced by the belief prevalent in our culture that since women kill rarely, she must have been moved by passion of some kind. This notion has a long literary history. According to Virginia Morris, women characters (the biblical Judith, Aeschylus's Clytemnestra, Lady Macbeth, Medea) who are "sometimes protagonist, sometimes criminal, and sometimes both at the same time, shaped AngloAmerican conceptions of violent women from the Renaissance through the victorian period and beyond." Although they may come from different literary traditions, they embody the same views: "violent crime is unusual, even unnatural in a woman; it is often the result of intense sexual passion; and it depends on deception or deceit for its success" (13). So, while our contemporary subject here is more pop culture than high culture, she fits into a historical tradition informing much canonical art (literary, visual, etc.) which we should not ignore.

Let us now turn to a closer examination of the texts, 
beginning with the earliest. The publication of Edward Bierstadt's Satan Was a Man in 1935 is a testimony to pearson's success in reviving interest in the Borden case. (The author even cites Porter and Pearson at the end.) Pearson's influence is evident in this representation of a guilty Lizzie, a "vengeful figure brandishing a bloody ax" $(40)$.

This is not a conventional mystery story which keeps the reader guessing the murderer's identity until the dramatic revelation takes place. Rather, it is a study of a murderer's mind. Carroll Lindsay hates his rich, drunken mother, and eagerly awaits her death so he can claim his inheritance. An unpublished writer, he is also a student of famous crimes. Bierstadt structures the story by having Carroll enter a dreamlike state while reading a true crime book, and then taking homicidal action. It puts a new slant on intertextuality. The first book he reads is an account of the Borden case. In his strange state, he "becomes" Lizzie. He sees through her eyes as she sits in the courtroom; he feels her emotions. While "possessed," he rips the head off his mother's beloved canary. Soon after, he finds a way to poison her gin and be permanently rid of her.

The next "dream" occurs as he reads about Jack the Ripper. This leads him to attack his mother's corpse while it is still resting in their house. His final 
Tansformation leads him to "become" Dr. Crippen, and he kills his new wife. Then, as if to emphasize the evil lurking here, another character in the story, simeon Gaunt, a criminologist, solemnly pronounces, "every man and woman on earth is a surrogate of God unless and until he or she becomes possessed of a devil" (169). Not only has Lizzie Borden attained the status of member of an exclusive club of famous murderers, she has also been linked to Satan.

Bierstadt devotes considerable space to her segment (pages 40-58), providing elements of her story and the trial. There is some deviation from the historical account, but one expects some inventive detail in a novel. This is a murder fueled by vengeance, hatred, anger, and a desire for money, and is reflected in Carroll's situation. Lizzie resents Andrew sneering at her, taking a second wife, and controlling her and Emma, keeping them financially dependent. Committing the murders exhilarates her. This treatment of Lizzie lacks depth, but is dramatic and striking. She may have sat quietly in court, but she killed with passion, and is immortalized as one of an elite, evil group.

Her next appearance is in 1939, in Marie Belloc Lowndes' Lizzie Borden: A study in conjecture. Mrs. Lowndes was a popular and prolific author known for her crime stories, "imaginative studies of actual murder cases" ("Lowndes"). The 1939 volume of Book Review Digest includes 
seven reviews of this novel, including the New York Times, New yorker, and Saturday Review. It is likely, then, that the book had a wide readership. Although she is described primarily as a mystery writer, the titles of some of her novels, The Heart of Penelope, The End of Her Honeymoon, cood old Anna, Cressida, suggest that they are directed to women. One should treat such generalizations with caution, but I suspect that Mrs. Lowndes' audience was mostly female, given her style and approach. A review of another of her books, Reckless Angel, in the same year, calls it "much more of a fairy-tale love story than a mystery story," and "pretty light stuff any way one chooses to take it." This reviewer, Isaac Anderson, writing for the New York Times, shows a response to the romance genre that was fairly typical among critics until feminists took up the study some years later, and their work proves useful to me here. The book about Lizzie, however, was praised for its "strict regard to atmosphere, morals, and manners of the time." (This is not surprising, since the author was a contemporary of Lizzie's.) In her preface, she states that if facts were enough to solve the mystery, we would have a solution. Therefore, we turn to "conjecture based on evidence." All explanations of the crime strike her as inadequate; she sees a major role for passion. Unlike Bierstadt's view, it is "the passion of love."

Thus, although based on historical data and focused on 
a famous crime, the novel is primarily the love story of a lonely spinster. While asserting that "it is one of the few, undisputed facts about her that we do know, Mr. Borden's younger daughter knew very few men in Fall River" (41), Lowndes makes use of Lizzie's Grand Tour to provide a suitor. The actual trip Lizzie made to Europe with a group of ladies a few years before the murders is tantalizing to contemplate. Very little is known about her activities, and there is certainly much fertile ground for the novelist.

In Paris, Lizzie meets two American men. One falls in love with her friend, and the other stirs interest in her. "What she now regarded as her friendship with Hiram Barrison was colouring and altering her view of life" (48). Lizzie falls in love with Hiram, a man with poor prospects, and keeps it a secret from her father. The passion seems to be all on her side, and the language expressing it is in the style of the classic women's romance novel. Back in Fall River, during a tryst in the barn, Lizzie "murmured in low, ardent accents, 'Oh, dearest, must we wait till--'" and she falters, as both know she means till Andrew and Abby are dead. Then, "he kissed her fiercely, thirstily" (105). "Hiram Barrison, mean and calculating soul, was but the vessel a cynical fate had provided for the filling with the heady wine of passion" (141). When they embraced, it "was as if she felt his full lips seeking and finding her guivering mouth. Yes, no one in the world mattered but the 
two of them, and their love for one another" (178-9). Here we see close adherence to an important convention of the romance novel, the "belief in the primacy of love in a woman's life" (Mussell xii). For Hiram, Lizzie is "still young, sweet-scented, and filled with love for him" (113), quite a contrast with the picture Angela Carter presents in her story, with her insistence on the odiferous aspects of nineteenth century life.

Abby sees Hiram sneaking out of the barn the night before the murders, and is upset. At her age, she is aware "of certain curious and sinister facts concerning the part sex plays in the hidden lives of many women," but she hadn't thought of Lizzie in this regard (136). When they confront each other, the language is highly dramatic, and also (to me) unintentionally funny. "There was something fiercely grim in the way that Lizzie uttered that commonplace remark, and it was followed with a fierce, grim statement. 'I want you to know that I've always hated you, Mrs. B.'" (153). Though Mrs. Lowndes was popular, I doubt she was known as an elegant stylist. But romance fans do not apply elite literary standards to their books. According to Janice Radway's study of a group of romance readers, style is not a major concern. A "well-written" story is one with a good plot $(190)$. Romances are characterized by repetition of the same, limited vocabulary and "overzealous assertion" which "combat ambiguity" and imply that all events are 
definitively comprehensible." Readers come to expect this: there is very little interpretive work for them to do (195$6)$.

When Lizzie is driven to murder, she actually rolls up ner sleeve to kill Andrew! Interestingly, the atmosphere of horror is only evoked after the murders, when the crowd. is in the street. Before then, it is calm despite the carnage. Lizzie is not portrayed as a monster, and this is consistent with the earlier part of the book, where she is a lovesick spinster inflamed by desire, whom the readers could find sympathetic. However, once she commits the more serious transgression of parricide, distance is needed. Thus, we have the scene in the street outside her home, where "after a horror-stricken pause, there arose a long drawn out moaning sound on the stifling air" (219). The novel ends with Hiram returning to Boston. He is told Lizzie will write to him, "but she never did." And so ends her story, as a broken romance. The primacy of romance is noteworthy here. After all, this was a sensational murder case and trial, yet these aspects fade into obscurity in the face of Lizzie's passion for her unworthy suitor, and her ensuing solitude.

Several factors keep this from being a conventional romance, however. Kay Mussell writes that key assumptions of romance formulas include "female passivity in romantic Falationships," and "reinforcement of domestic values" 
(Eantasy xii). Lowndes draws on standard biographical data for some of Lizzie's characteristics, so we hear echoes of real-life uncle Hiram Harrington in the description of the heroine as "self-assertive" (3), with a "masterful disposition" (2). Both Lizzie and Andrew are "haughty, determined, and bent on always getting their own way" (132). An old friend of Lizzie's mother finds her "almost repellant... independent in her manner.... a good opinion of herself," while another enjoyed Lizzie's "vitality" (74). This is not a typical passive heroine, in personality or behavior. She is aggressive with Hiram, not to mention her parents.

This story does seem to subvert "domestic values," since she kills her parents and winds up without a husband. However, Mussell points out that one type of romantic novel is the "anti-romance," which reinforces the "assumptions of the form." Here, "the heroine behaves in such a way that she cannot be rewarded with marriage in the end." Marriage still remains desirable, and inverting the plot makes the story "a cautionary tale rather than...a model to be emulated" (Handbook 317). Kill your parents and lose hope of finding a husband.

One of the essential elements of the romance is "belief in the primacy of love in a woman's life" (Fantasy xii), and this is never challenged here. In fact, Mussell claims that "romances rarely challenge the social order, and they do not 
urge women to recognize oppression or to revolt; instead, they reinforce the value of traditional roles in a changing society" (xi). However, other critics argue for the presence of subversive potential in the genre. Radway observes that the act of reading the romance may be more significant in some ways than the text itself. It allows women to claim time for themselves, to enjoy the pleasure of relaxation and escape from the continuous demands of caring for their families $(86-7)$. Some of the women Radway studied even said that the situations of certain heroines made at least some readers reconsider their own lives. Her group felt that their reading had helped them become more assertive (218). Rather than being mere "light stuff," the role this genre plays for its female readers is complex, affirming "love" and marriage, yet opening the door to questioning and protest.

These tensions and others are discernible in this novel. By using many of the conventions of the romance novel, Lowndes attempts to contain an unruly subject and place her in a familiar literary framework. She portrays Lizzie as physically attractive, with a "sensuous nature" (71). In the world of the romance, all women, including Lizzie, yearn for a loving husband. But she is a killer, and threatens to disrupt the configuration into which she is placed. The novel was published in 1939, a time of Depression at home and economic collapse and fascism abroad. 
The tension I see may be expressing a mixture of nostalgia for verities and a recognition of brutality. A desire to reaffirm traditional roles and stability shapes this retelling of the legend. While "there had always been something unusual about Lizzie Borden" (198), Lowndes tries to domesticate her, to make her comprehensible as the woman who committed a crime of passion. She may have escaped punishment from the judicial system, but her gender is subjected to another disciplinary power. In a complete reaffirmation of the status quo, Lizzie is denied love and marriage, recognized in the novel as woman's primary goal.

Many decades later, another very popular and prolific writer took up the Borden case. Evan Hunter's Lizzie (1984) has some points in common with Lowndes' novel, but is also very different, and reflects the changes in our culture. He, too, mines the European trip for its plot potential, and emphasizes the passion of Lizzie's crime, but there the similarities end. Instead of flowery and overheated romance prose, we find a crisp, witty, and humorous style. The structure is cinematic, alternating between Europe and the Fall River of 1892. Hunter makes much use of the historical record and the biographical writings which fashioned the legend, and embellishes these using the storyteller's license, resulting in a more detailed representation of Lizzie. In his Afterword, he mentions his sources, including the trial and inquest testimony, which he quotes 
extensively in the novel. He also cites the books by Victoria Lincoln and Agnes De Mille. Newspaper sources are also used effectively to lend an air of historical athenticity. In the course of all this historical econstruction, the story of the Fall River murders is revealed.

There is a dichotomy in the novel. The public lizzie (based on history) is presented in serious and sober episodes, whereas the private Lizzie (the author's invention), acts out her story in passionate and amusing scenes. The public Lizzie coincides with and perpetuates the legend. At the inquest she is stubborn and adversarial. She shows unnatural calm and "masculine strength." The haunting gaze is emphasized: "He had heard them speak of Lizzie Borden's eyes...almost staring...cold...penetrating" (24). By all appearances, this is the sinister murderess her enemies have long portrayed.

But there is another side to Lizzie, revealed in the flashbacks to the European trip. In England she meets Alison, a beautiful, rich, witty young married lady who befriends her. Lizzie is stricken with influenza, and Alison nurses her. The other American "girls" continue on their Grand Tour, while Lizzie retreats to Alison's villa in Cannes to recuperate. About three-quarters of the way through the novel, Alison seduces Lizzie. This private Lizzie is much more attractive and desirable than the one 
portrayed in the press and legal proceedings. The contrast between Alison and Lizzie plays up their narrative functions as the archetypal experienced woman of the old World who shocks and corrupts the innocent young creature from the New World. Lizzie is at first embarrassed by this new relationship, but she enjoys Alison, whose "corruption" extends to an unrepentant incestuous relationship with her twin brother. Eventually Lizzie comes to the realization that Alison is "her own twin" (360).

Alison has a strong feminist sensibility, and makes snide remarks about the patriarchal system. She speaks of how men control and dictate to women in society, and disparages the "myth of ideal womanhood." Her sexual adventuring is a form of rebellion, though her public image is one of married respectability. Lizzie does not at first seem rebellious, but as she identifies more with Alison, she moves toward her own rather spectacular act of rebellion. The moment is presented dramatically. From the courtroom scene where Lizzie is found not guilty we cut back to August 4, when she kills. Lizzie is having an affair with Bridget the maid. When Abby catches them in bed together, she calls Lizzie a monster. Flying into a rage, Lizzie kills Abby with a candlestick. Soon Andrew comes home, and begins to guess the truth. He reviles her, and threatens to tell the police. Lizzie strikes out passionately with the hatchet. Alison may be out of the picture now, but her 
mepiration remains as her words linger in Lizzie's consciousness:

Our greatest secret, our supreme strength, is that no man on earth, no father, no son, could dare admit that a proper lady--his daughter, his sister, his wife--would ever commit a breach that seriously threatened his superior position in the society he has constructed and which he will support with his very life. For should he once believe of any one of us that we might so rebel against the absurd rules and regulations proscribing the periphery of our lives, then he must perforce believe that we are all capable of bringing down his elaborate house of cards and thereby destroying his faith in the cherished myth of ideal womanhood (425-6).

with this in mind, Lizzie resolves to play the innocent and let the patriarchal system work for her.

Hunter makes convincing use of the feminist critique of patriarchy available at the time he wrote the novel. A double criticism is implicit in the story--not only is it a system which limits and oppresses women, but its blindness causes a murderess to go free. The use of lesbianism, which can be viewed as another rejection of patriarchy, as a significant element in the plot is in strong contrast to Lowndes' novel, though both follow a similar pattern. No 
Radclyffe Hall, Lowndes had to find a heterosexual love Interest for Lizzie, but Hunter could use homosexuality because times changed and it is now acceptable in popular fiction. It is still, however, a way to both contain and varginalize the character. Despite recent liberalization of some of the discourses on homosexuality, it remains notwithstanding marginalized across any number of contemporary social formations. Hunter's use of these elements in the novel indicates that the reader is being constructed as a sophisticated, "liberal" subject who will not be scandalized by them.

While the novel can be read as an unpretentious and entertaining story, it also questions the notion that a famous historical character can be recovered. The "factual" material is thoroughly integrated with the fictional. The author's Afterword makes a point of distinguishing between facts he used and material he invented. The effect of the novel, however, is seamless, and suggests that it is all fiction. The "real" Lizzie is as much a construct as the imaginary one.

Taking another approach to the legend, walter Satterthwait's Miss Lizzie (1989) is an entertaining detective novel in which Lizzie is both hero and perhaps villain as well. The narrator is the grown-up Amanda Burton, recounting the memorable summer of 1921, when she was thirteen years old, and discovered that her neighbor at 
the Massachusetts seashore was the elderly Miss Lizzie.

Amanda knows the famous verse, and is excited about meeting its subject. Lizzie is very gracious to the young girl, who immediately feels a sense of kinship with her. We quickly see parallels between these two. Amanda adores her father and loathes her tiresome, overweight stepmother. Her own mother died when she was an infant, as did Sarah Borden. Even the surnames are similar. Amanda's stepmother is uysteriously murdered in the guestroom while the girl is sleeping nearby. The murder weapon is an axe. It is August and oppressively hot. Like the man said, it's déjà vu all over again. It is hardly surprising that when Amanda discovers the corpse, she turns to Lizzie. Because of her notoriety, Lizzie falls under suspicion at first, but the real suspect is William, Amanda's brother. Police detectives are, of course, hard at work on the case, but so is Lizzie, and she turns out to be a clever detective. In a dramatic scene, she wields a hatchet against the hatchetcarrying murderer, a most unpleasant woman neighbor who is after Amanda, and kills the villain.

Satterthwait draws on the historical material, shaping it to fit his story. Familiar names, such as Bowen and Hedley, appear in the text. Drawing on Lincoln, he includes the possibility of Lizzie having killed Abby during a fit, but refrains from making conclusive statements about Lizzie's past. Like the actual photograph of the middle- 
aged Lizzie, Satterthwait's character wears pince-nez, and has pale, large blue eyes. In this story, however, it is her big white cat who has blank eyes, not Lizzie. She is actually quite appealing, with her silver-white hair, fine skin, dimples, and "extraordinary smile" which changes her "stern, severe face into one of great liveliness and charm" (7-8). This is the private Lizzie whom few see. She laughs easily, and in the privacy of her home smokes cigars and practices fancy card tricks which she teaches Amanda. The woman Amanda sees is kind and strong-willed, and terribly lonely.

She is also multi-dimensional, a woman of deep passions. Amanda sees her in a state of great unhappiness, and in a murderous rage. The possibility of her guilt is always kept open. At one point Lizzie speaks of Nance, her actress friend, whose Lady MacBeth impressed her because "she was able to make the audience feel that even monsters have depth" (203). (There is an echo of Pearson here, who compared Lizzie to Lady MacBeth.) Finally, years after this adventure, Lizzie leaves Amanda a memento in her will, and includes a six of hearts card, which in the Nikola system she taught the youngster is mnemonically connected with the mother and a hatchet.

While drawing on previous texts and the legend and the conventions of the detective novel, satterthwait has produced a fresh and successful story. Cawelti points out 
that "the power to employ stereotypical characters and situations in such a way as to breathe new life and interest into them is particularly crucial to formulaic art of high quality." One way to revitalize a stereotype is to add "significant touches of human complexity or frailty to a stereotypical figure" (11-12), which Satterthwait does. This is an eccentric, likeable Lizzie who saves a young girl and sees justice done, but she is also a woman dressed in mourning, for a past filled with death and unexplained sorrow.

The fundamental ambiguity which Lizzie embodies gives the novel an edge. Jim Collins writes that some theorists of popular culture see detective fiction as repressive. In its process of resolution it asserts the centrality of the State and the status quo (28). He rightly disputes this view, claiming that there are discursive alternatives and that power can be located in more than one source. In detective novels, "not only does an alternative sense of justice often develop which problematizes implicitly or explicitly the nature of 'law,' but...a private sense of justice throws into question the public one." Even "the very possibility of a state justice appears oxymoronic." At the end of the story, "the typical isolation of the detective...is both physical and judicial." collins attributes "the inability of most ideological analysis to conceive the detective (and by extension popular culture) as 
a third-term alternative to standard dichotomies" to the "rigid binarism of that analysis" (30-1).

satterthwait provides a good example of detective fiction that retains subversive elements. His heroine is isolated throughout, both legendary murderess and detective. While he uses standard devices and even includes a romantic subplot (Amanda is attracted to a young lawyer involved in the case, and tells us she eventually married him), he takes no steps to diminish the sense of uneasiness the novel creates. He makes no final judgments, and leaves the reader on the hook. A woman who quite likely killed her parents is a sympathetic character, who here commits justifiable homicide. She triumphs over the legal system, showing herself to be smarter and stronger. Amanda's stepmother was a nasty woman, and no one regrets her passing, though they are compelled to seek out her murderer. If Lizzie and Amanda and the Burtons are the respectable defenders of the status quo, we have to wonder just what that is. Family relationships and responsibility for our actions and ideals about justice are called into question, rather than buried under a blanket of sentimentality. With Lizzie, the author has a built-in element of subversion, and he uses it effectively.

The latest novel based on the legend, Elizabeth Engstrom's Lizzie Borden (1991), also plays on subversive elements, although it is easy to overlook them because of 
Ingstrom's breathtaking incompetence as a writer. She is so stunningly bad, one is tempted to dismiss the whole business out of hand. After the gory murder of Andrew, rendered in self-consciously artsy prose, Lizzie, who is presented (confusingly) as being in two places simultaneously, stands horrified in the barn:

Pear juice covered her hands, and rivulets had run down her forearms. Dust from the barn stuck to it, leaving dark trails.

I think there's something wrong with me, she thought. Surely other people didn't think about their parents in the same way. (338)

The novel presents the familiar story of the Borden family and the murders, and creates the impression of a dedication to facts by opening with the floor plans of the house on second street. All the primary historical characters are present, as are various details from the standard accounts. There is also an epilogue which informs the reader about the historical aftermath of the murders, further creating a sense of "authenticity." A glaring inaccuracy is present though in the statement that Lizzie "carried on a flamboyant affair with actress Nance o'Neil" (342). Very little information exists about their relationship, making this a distortion of the historical record to accomodate the author's characterization of Lizzie. Engstrom creates new elements in plot and character, some of which are jarring 
because they are so obviously features of our contemporary culture, and clash with the 19th century setting. The Bordens in 1892 are a model "dysfunctional" family. Andrew is overly dependent on Lizzie, who resents Abby. He is nasty and miserly, while his wife is useless and passive. Emma is bitter and jealous. They could all be on "Oprah." so far, this is a credible, if unpleasant picture, but then Emma is portrayed as a secret drunk who goes off to New Bedford on week-long binges which involve not only alcohol but violent sex with strangers. This ludicrous element adds nothing to the plot, is unrelated to the murders, and disrupts the already hard-to-maintain illusion of victorian life. It is hard to believe that Emma could keep her secret in that closed little world. It is one thing to hide a bottle at home, but another to act out in public and expect to keep it quiet.

Then much is made of a self-help book (with a strong 1980 s or 90 s flavor) Lizzie gets from a friend. It sounds suspiciously New Age. According to the New Age Encyclopedia, this movement "can be defined by its primal experience of transformation. New Agers have either experienced or are diligently seeking a profound personal transformation from an old, unacceptable life to a new, exciting future" ("Introductory Essay"). Ironically, a prominent emphasis of New Age thought is healing, while here the path leads to murder. The New Age goes seriously and 
perversely awry in Lizzie. The book, Pathways is about taking charge of one's life, and emphasizes the reader's "myriad selves" (190). An example of one of the "lessons" llustrates my point:

I now claim that which is divinely mine. I claim absolute control over each fragment of my personality, to be strengthened through purposeful, conscious unity. I now will that the Divine Power which motors the Universe now deed me the control over my own destiny. I now claim that I, and no other, am the architect of my future. I now command my rightful, unique place in the order of all material. So it is, so shall it be.

This also looks like an "affirmation," which in "New Age metaphysics is a statement spoken in the present tense about a condition which the person making the statement hopes will become true in the near future." It is related to prayer. For spiritualists and theosophists, affirmations coupled with creative visualization brings the ideal from the astral to the material realm. "In their strongest form, affirmations become decrees, in which one demands that the universe produce the desired object or reality" ("Affirmations"). Some of the strange later developments in the story, such as Lizzie being in two places at once, might well be a macabre use of visualization.

In keeping with the Pathways model, Lizzie is shown to 
already have a dislocated sense of self. She sees herself doing odd things that she doesn't always remember, such as stealing from Abby. This trance-like state echoes victoria Iincoln's theory about Lizzie's "spells." But Engstrom takes it to surreal lengths where Lizzie sends a self out on a walk, and Ema sees it. Surrealistic elements can be effective, as they are in Angela Carter's story, but they fall flat here, perhaps because they are related to visualization and not conveyed effectively. Emma also has periods when she is "gone away from herself," when she is drinking and experiencing loss of control. This relates to Pathways, which is about control. It is seen as an impetus to be independent and self-reliant, to release repressed emotions. There is an implication that it is a corrupting feminist work which attempts to undermine the status quo.

Lizzie takes it very seriously, and begins a process of relaxing her inhibitions. She has a lesbian affair with an old school friend. Then she falls in love with the woman who is Andrew's mistress, though Lizzie does not know this. As she gives free rein to her sexuality and emotions, we see that Pathways is leading her to trouble. Wilhelm Reich, whose work is respected by New Agers, "argued that repressed sexuality was the root cause not only of individual ills, but also of the systemic social dysfunctions that have plagued Western Civilization" ("Reich, Wilhelm"). Lizzie's "liberation" does not lead her out of dysfunction, but 
further into it. After her crime, the "architect" of her future is quick to say, "It was not my fault" (338).

When the time for murder approaches, the anger raging within her becomes stronger. Her selves split, and she is simultaneously in the barn masturbating and in the house, bashing away at Abby with the axe. Passion and rage are unleashed in a fatal combination, and it is not a pretty scene:

Lizzie pounded herself as she imagined pounding Abby, the thrusts to herself more and more brutal. She loved it, she hated it, she wanted to hurt, bite, squeeze, kill. She rolled, curled over, in the hay, muscles twitching and throbbing as the hatchet continued to lay blow after blow on her stupid stepmother's head. The orgasm shuddered to a violent conclusion.

When it was over, she cried. (329)

Lizzie may have many selves, yet they lack the multidimensionality which Satterthwait created in his novel. However, while the point is poorly rendered here, it is important. The critique of the traditional family, with its appearance of respectability hiding all manner of nastiness, is also worth noting. Although Engstrom deals awkwardly with the issue of control, it is a key element in the Borden case. The components for a provocative representation of the story are present, but ineptly used. 
Engstrom questions not only the familial order, but the larger social order as well. The lesbian romance here, as in the other novels, challenges the patriarchal status quo. Lizzie's passion makes her powerful, not a desirable trait in a female. And we have to ask ourselves, is the Fall River depicted here before the murders an ordered world? I think not. Rather than seeing the murders as the violent disruption of a normally ordered and peaceful world, which will be restored when justice is done, they are the inexorable outcome of the conflicts which lie hidden in that world. Lizzie Borden, victim of dysfunctional family, product of environment, self-help fan, and powerful sexual force, has now acquired the cultural trappings of the (nineteen) nineties.

How this is received by readers is an open question. Jerry Palmer notes that "the subject that reads is always already constituted in the proliferation of discursive acts in which subjectivity is set up in the first place" (Rotboilers 88). Developing an accurate, reliable profile of these reading subjects seems to me as likely as getting the "truth" about Lizzie. The contemporary intrusions in the novel which I find so annoying are certainly part of the web of discourses in which we now live, and would be familiar to many readers. Perhaps some would enjoy this modern reworking of the legend. However, many readers have developed expectations about tone and coherence, and 
intelligent treatment of a historical period, and these are not met in the novel. There is a cacophony of languages here--history, feminism, pop psychology, melodrama, and they clash. Is this a historical novel, a horror story, or an object lesson in New Age ideas gone bad? The sub-genres are so mixed up that the illusion of authenticity disappears, leaving confusion in its place. It may not be a satisfying book if viewed with conventional expectations, but it incorporates Lizzie into a new cultural context, and it proves even "bad" books can be interesting.

Some of the issues Engstrom raises are met head on in Angela Carter's short story, "The Fall River Axe Murders." She explores them with wit and intelligence. This extraordinary story begins on the morning of the fatal day in August, and remains poised there, as the circumstances leading to this moment are described. Carter draws freely on previous historical/biographical accounts, so we hear echoes of Pearson (on clothing in New England), Lincoln (Lizzie's spells), and the trial testimony. This intertextuality is common in Borden texts. It is also, according to Elaine Jordan, a feature of Carter's style, which "yokes disparate effects: the banal and the extraordinary [two words which capture, if anything can, the heart of the Borden legend], the prim and the offensive, the baroque and the offhand. The unmistakable boldness of this style is produced by its collisions, its very active 
dependency on previous texts, which is a reader's rewriting, and a rewriting of readers" (123).

History here is both foregrounded and interrogated. Through her use of descriptive detail, Carter creates a strong sense of time and place. She evokes the period with much sensual detail and an emphasis on discomfort, "the itching, oppressive garments," and great range of foul odors. This "refusal of nostalgia" distinguishes her from most of the other writers studied here, and is typical of her narrative style (Jordan 123). But rather than maintaining the illusion of a recaptured past, she places ruptures into the text. One is the authorial voice commenting on the past from the present moment, emphasizing the impossibility of ever completely recovering what has gone before. Referring to the daily lives of the Borden sisters, she contemplates their activities, "napping...sewing...writing...staring vacantly into space. I can't imagine what else they might do." There are also surreal distortions in the environment. On the morning of August 4, all is white--the sun, "a sky already white, the shadowless light of New England like blows from the eye of God, and the sea, white, and the river white." The world is white like a sheet of paper on which the events of that day will be inscribed.

Carter fills her pages with a carefully crafted narrative. Historical data are transformed into art through 
images, stylistic devices, tone and structure, and the artistry is revealed as a representation, one possibility among many. The audience is called on to recognize this. carter refers to the way "our imagination" always equips "Lizzie Borden with an axe," "just as we always visualize st. Catherine rolling along her wheel, the emblem of her passion." And later, as she surveys the inhabitants of the house, she decides we do not need John Morse (who really was there) for this retelling. "Write him out of the script." Readers have a part in re-creating this event, and carter makes that role unavoidable and concrete.

She "takes apart the accepted morality tales that constitute the sacred cow called History, and exposes, through her own manipulation of them, the cultural conventions that shape our view of the past" (Krauss 15). Her story shows "the multiplicity of readings (and tellings) that fit any historical event" (16). This Lizzie will murder because her life is empty; because she is filled with the passion of sexuality and capitalist acquisition; because she has strange spells; because she must break out of this house where every door is locked. It is no coincidence that Jordan detects a movement in Carter's work against the Enlightenment world of Locke, where "ideas are derived simply from sense-perception," a world of "locks, cages, and fixities" (125). This is a world Lizzie shatters.

It seems to me that Carter's goal is similar to the new 
historicists'. However, rather than dividing her text into historical anecdote and discussion of a literary text as some do, she collapses these into each other. Her story is anecdote, literary text, and interpretive process, allowing her to reexamine a set of cultural givens. Joel Fineman sees the function of the anecdote as opening and destabilizing "the context of a larger historical narrative that can be seduced by the opening anecdote" (Hart Ariel 98). This story carries the same reverberations. It is not only about a peculiar murder, but a critique of patriarchy and capitalism.

The good old days are shown here to be horribly oppressive. Images of heat, illness, death and violence predominate. Lizzie's whalebone corset "took her viscera in a stern hand and squeezed them very tightly." The weather "clings like a low fever," the morning is a "furnace." The "reek of fleshly decay you always carried with you was overlaid by that of the embalming parlour." In this atmosphere, there is no hope for the women. They live in a house "full of locked doors that open only into other rooms with other locked doors," a metaphor for their lives. Emma's room is "a dead end." She "has no life." Nor does Lizzie. Both "remain in a fictive, protracted childhood." Mrs. Borden spends her life in joyless gluttony. For them all, the "days open their cramped spaces into other cramped spaces and old furniture and never anything to look forward 
to, nothing."

Their lives are controlled by Andrew, who "owns all the women [in the house] by either marriage, birth or contract." In him the critiques of patriarchy and capitalism are linked. None of the other texts even remotely considers him from a humorous standpoint, but Carter's alliterative description brings a note of amusing irreverence--"old Borden will perambulate the perspiring town, truffling for money like a pig until he will return home mid-morning to keep a pressing appointment with destiny" (39). If Lizzie is the mythic lady with the axe, Andrew is the classic capitalist pig. His hobby is "grinding the faces of the poor." Accumulation of property is his passion, as he revels in "an orgy of investment." In this family, where emotions are repressed and doors locked, the only manifestation of passion is the desire for profit. Carter is proposing a new twist on a common theory about the crime. Kany find the motive of simple greed to be unsatisfactory, and she suggests here that it is not so simple after all, but marked by emotional ramifications. When Lizzie struck her blows, she attacked the dominant systems of patriarchy and capitalism, and the family dynamic which made the inhabitants of the house on second street so miserable. Lizzie tries to convince her friend Alice Russell that "the entire household was under siege from malign forces without" (50). Carter shows these forces both without and within. 
In retelling the story, Carter reaches beyond history to myth and folktale, a tactic she favors in other texts as well. As she describes photographs of Lizzie, she focuses on those famous eyes. They are "mad eyes...fanatic's eyes," which may cause you to think of Red Riding Hood and the wolf (54). Once you know you are looking at a legend, you cannot see her as an ordinary historical subject. (There are other references in the story as well, to "the sleeping beauty," and Bluebeard's castle, to emphasize that Lizzie has the status of a folktale character.) Then Carter pulls us back to history, comparing Lizzie's jaw to that of "a concentration-camp attendant," and again, "such eyes..." She inserts the audience into the scene, questioning her former references to madness, "for don't we all conceal somewhere photographs of ourselves that make us look like crazed assassins?" There is a significant point to all this. To refer to Lizzie Borden is always to combine the historical subject with the legend. Our eyes cannot see an essential Lizzie because none exists, but also, we are always looking through lenses tempered by various discourses and desires, even when we gaze upon her likeness. We are not only spectators, but participants. And it isn't that history doesn't exist, and there aren't truths to be found, for after all Lizzie and the murders were real, but that the whole business is problematical.

Carter demonstrates the power of the legend by 
refraining from showing the murders. It isn't necessary. She creates the powerfully foreboding atmosphere, where nerves are "taut as the strings of a wind harp" (56), and the reader provides the rest. In her playful, parodic, and deadly serious fashion, Carter brings us eye to eye with the Lizzie Borden she and we have conspired to create, and along the way lets us realize she is also shaping us as readers.

A much less complex but still interesting story incorporating the legend is Robert Bloch's "Lizzie Borden Took an Axe..." Rather than providing the intellectual challenges that Carter does, this popular author (of Psycho, among others) draws on the conventions of gothic horror to provide simple entertainment. In the process, he makes it clear that Lizzie's act was no ordinary crime. Nor are the two characters, Jim and Anita, ordinary people. Anita lives in a spooky old house with her wicked uncle who boasts of having occult powers. She is often troubled in her sleep by an incubus, or demon. Jim, the narrator and her lover, gets a call for help from her, rushes to the house and finds the uncle dead, his head "split open and crushed to a bloody pulp." Obvious parallels to the Borden case emerge. It is a hot, still summer day. Anita's alibi is that she went out to the barn to look for sinkers, and found the body when she returned. Jim recognizes this story. She had one of her "dreams" in the barn, and he interprets this as possession by Lizzie Borden (echoes of Bierstadt). Since Anita does 
not know the story, Jim tells it, and the Borden legend is recited to yet another audience.

After a lull in the action, Jim senses someone sneaking up on him. It is Anita, her face obscured by a black cloud. She is "possessed" by the demon, and holding the bloody axe. Anita faints, Jim takes the axe, and is inspired with the idea that Lizzie was possessed as well when she killed her parents. Exhausted, he falls asleep. When he awakes, the axe is gone. To his horror, he finds it buried in Anita's head, and there the story ends. Just before this grisly discovery, he wonders if he also might have been visited by a demon during his slumber. This implies he was not himself, but the victim of evil forces outside himself--the demon, the satanic atmosphere of the house. It also suggests that demonic possession can strike anyone, and cause us to kill those we hate (the wicked uncle, the elder Bordens) and those we love (Anita).

Lizzie is not the primary character in this story, but she is nevertheless the powerful historical subtext which shapes the narrative. Lizzie the person gets a little attention, described as a woman of good reputation, but some found her "temperamental, even eccentric," qualities often mentioned in the biographical texts. However, the emphasis here is on the legend. The story opens with the famous verse and repeats it later. The sensational murders and trial have taken on a life of their own, which now 
influences this new narrative. They have become transcendent events.

They have also become useful tools in a genre which draws on the gothic tradition. Bloch writes to convey a delicious thrill of horror. The technique is so blatant that the reader can enjoy this grisly adventure and feel entirely safe. In the classic gothic novel, "the moral function of the unexplained is subordinate to the aesthetic function of producing a shudder." But the mystery continues to fascinate us, perhaps because "at the core of Gothic is human reason trying to grapple with that which constantly threatens to exceed its bounds" (Palmer Thrillers 124-5). Bloch could be suggesting an explanation, through his technique, of the reason for the long fascination with the Borden legend. Carter sees folktales and myths, Bloch sees Gothic. The legend is flexible enough to accomodate them all.

To speak of Lizzie Borden and poetry in the same breath and with a straight face is a mighty challenge. After all, her fame has been carried to the ends of the earth by the famous quatrain. It was my own introduction to Lizzie when, as a young child in the European immigrant subculture of Yontreal, I learned this rhyme and marvelled at how colorful Americans were, compared to the bland, law-abiding Canadians. This is not the sort of rhyme which is treated 
as a work of artistic merit, being a classic doggerel poem, but it captures the essence of the event dramatically, expresses a cheerful irreverence, and is memorable. Its origins are unknown, as it sprang up in the folk culture, and of course literary critics devote themselves to study of works on a higher plane.

A more substantial but still lighthearted poem also appeared in Lizzie's day to regale Borden fans. According to John David Marshall's introduction, A.L. Bixby's "To Lizzie" was probably published in 1893. Several stanzas are quoted in one of Pearson's books. Mr. Bixby was a newspaperman working for the Nebraska State Journal in 1892. His poem was published in an anthology of his verses in three editions, 1895, 1897, and 1907. Poetry has a notoriously small audience, but works of this type, in a popular vein and accessible, may well have had more than the usual handful of readers. It is not known if he attended Lizzie's trial, but it is possible. He certainly was knowledgeable about it. The poem focuses on Lizzie's trial and the spectre of the death penalty. Grim though the topic is, it is handled with humor. At one point it addresses a major criticism of Lizzie which is widely discussed in newspapers and books, her stoic, unfeminine demeanor:

You have borne up under all, Lizzie Borden, with a mighty show of gall, 


\section{Lizzie Borden;}

But because your nerve is stout

Does not prove beyond a doubt

That you knocked the old folks out,

Lizzie Borden.

It is interesting to see this expressed by an observer at that time. We have noted Porter's remarks about her manner, and the prosecuting attorney's as well. Here we get the sense that this was also a common topic of discussion in 1893. We also see that there was some resistance then to the stereotype of proper female behavior. Just because women were expected to be emotional did not mean that all people condemned those who, like Lizzie, behaved otherwise. Bixby's poem is a genial reminder of Lizzie's immense popularity. It also expresses the views of the pro-Lizzie faction with unmistakable clarity: "Many do not think that you / Chopped your father's head in two." This appropriation of Lizzie into the popular sphere via doggerel is not so far removed from the contemporary eruption of jokes about notorious transgressors like Jeffrey Dahmer or O.J. Simpson. Whether these jokes will survive is one question. Another and more intriguing one is why the "popular" continues to reproduce Lizzie so long after her moment of media attention.

These hearty, amusing rhymes are what we might expect to encounter on the subject of Lizzie Borden. But more 
"serious" poets in the realm of high culture have also been inspired by her. Ruth Whitman's "The Passion of Lizzie Borden" is the title poem in one of her volumes. Whitman weaves many elements from the historical/biographical accounts into the poem, but ventures far beyond these in her representation of Lizzie.

The predominant images are heat, pears, and blood, all of which relate to nature and female sexuality. Lizzie feels "tidal waves from the sea" and "sunstorms, volcanoes, astral debris, / until she was pregnant with a pregnancy / that puts an end to wishing." Anger intersects with nature and sexuality. Whitman's one deviation from the historical record is significant. Andrew always wore a gold ring Lizzie gave him. Here, he gives her a ring, which "pinches her finger," evoking the ambivalence of the relationship. Her life is being squeezed out of her. The "house has killed the girl she was." She must "take life to make life," to stay alive herself. Her rage is physical, mental, sexual, and powerful. It extends from the earth to the moon, stars and sky. Yet the reasons for these cosmic feelings are only hinted at--she is repressed, trapped in this life. There are striking resemblances here to sylvia Plath's "Daddy." The daughter in that poem also feels oppressed, raging with conflicted feelings for her father. "I used to pray to recover you," but daddy "bit my pretty red heart in two" $(222-4)$. The intensity of her feelings 
and need to escape the oppressions of this family romance require her to kill him, albeit symbolically. She must "kill" him and say the forbidden words to free herself. plath openly expresses feelings that are taboo. Lizzie picks up the axe.

Ironically, the compulsion to kill to live could also refer to the act of murder as Lizzie's path to immortality, endowing her with the status of a legend. The necessity of the act is also expressed in "Who's to judge me?.. I feel hallelujah in my hips." There is a disturbing sense of righteousness here, and a sense that she is larger than life and can no longer be contained by convention. And so the poem ends--"She raises the ax." This powerful image is ridiculously close to "Lizzie Borden took an ax," yet it is also worlds away from it. This is larger than an isolated act of domestic violence and more serious than a pop culture legend. Lizzie has taken on mythic proportions as she stands, poised with the axe. The rupture created by her passion contrasts with the mundane details of the pear tree and the ironing of handkerchiefs. The spinster from Fall River is transformed into a force of nature, a female principle which becomes homicidal when repressed. Whitman rightly implies that because there is such power in the scene of a daughter's parricide, as Plath has demonstrated before her, it has found its place as a fixture in our culture. 
Another serious poem followed ten years later with the appearance of Stephen Ronan's Our Lady of Fall River. Published in a limited edition of 250 copies, it will never have a wide audience, and probably is sought out mainly by Borden fans. The epigraph is a version of the famous quatrain. In a poem where two diverging elements intersect, the real and surreal, the old rhyme is part of the familiar, historical narrative we know by rote. Ronan uses historical details like the Negro pallbearers Lizzie requested for her funeral rites, and her shoplifting. He even includes photographs in the text--Lizzie's grave, Maplecroft, the house on second street, to fully ground the poem in the materiality of the events. The narrative movement is a walk through contemporary Fall River at night, with attention to the places marked by the Borden case. The narrator feels her presence: she haunts Fall River as her "images persist" in the "jumprope song," "photos and paintings," and those buildings. He seeks her, trying to know her, to envision her: "I prowl behind the carriage house / To look within your veiled rear porch." Traces of Lizzie persist all over town, and the psychological implications of his search here are obvious.

And here the poet enters another dimension. In pursuing her, he finds a surreal, fantasy world which contrasts with the ordinary streets of the city. There are hellish images, as desolation and "hell-spawn" accompany the 
narrator and Lizzie on their stroll to "the actual inferno / of granite mill buildings." The murder of Abby is rendered in surreal images: "the hatchet throws sparks / That ignite the magnesium walls. / Petals of flame drift down..." The scene of horror has an odd, perverse loveliness, whereas Andrew is described in grisly terms--his greed, bad smells, black blood. Is this because she enjoyed killing Abby but not Andrew? Whatever the answer, the strangeness and sense of evil are striking.

In an ironic note, Lizzie is "Our Lady," the implied opposite of the Virgin Mary. The poem is organized into sections, Invocation, Evensong, Angelus, Matin. The quasireligious tone is obviously parodic. The perverse narrator worships Lizzie, "o perfect criminal!" The tone of admiration evokes Pearson (and many fans), convinced of her guilt but fascinated and smitten by her enigma. And the "Lady of Fall River" comes straight from Pearson's letter to Roughead. Is the narrator identifying with Pearson or mocking him and all those who have become abject fans? I suspect it is both. He is also targeting institutionalized religion. Anyone familiar with the case will recall that Lizzie was active in her church, and supported by clergymen throughout the trial. The well of christian charity ran dry after the trial, however. What are we to make of an institution which claims the moral high ground and defends a murderer? 
In another example of intertextuality, Ronan considers Lizzie's state during the murders in lines which may be a reference to Whitman's poem, published earlier:

The recent cornball language

On your "passion"

Missed the desire that flowed

As ultraviolet light.

How this desire is different from passion is not clear. Ronan's poem is evocative, and raises many questions. Surely there is no way to comprehend Lizzie's state of mind, to pinpoint in a material sense her passions or desires. To see her desire as a dangerous form of light strikes me as a fine visualization of an elusive concept. As the poem closes, Lizzie levitates above the city and we are left with fragments--axe, skulls, flakes of blood, a bedspread. There is "A cardboard echo / of your silver nitrate smile." Ronan's interest, like Carter's, extends beyond the facts of the case to its cultural significance. All we have of Lizzie here are fragments, distant images which we piece together and place into our present moment, to make her present to ourselves.

Drama seems a natural vehicle for the Borden case. A troubled family, sensational murders, wealth, and mystery are elements which can be combined to create a successful play. Wendy Lesser sees "a profound and historical link 
between murder and theatre" (7). The courtroom scenes alone have great theatrical potential which has been realized by an astute group of legal professionals in the Fall River/New Bedford area. They have on several occasions presented the reenactment of the trial and also Lizzie's inquest testimony, faithfully using the transcripts without embellishment. I have seen a performance, and found it riveting. While some court proceedings may be as dull as watching grass grow, these, based on the historical texts, were as absorbing as anything the art of the playwright could contrive.

A number of playwrights have been inspired by the case. Some use it directly, with actual names and places, while others disguise it. Nine pine street by John colton and Carlton Miles brought the Borden legend to Broadway in a production starring Lillian Gish. The names and some details are changed, but the story is the familiar one. Indeed, this play is based on a play by william Miles and Donald Blackwell, entitled Lizzie Borden, with a 1930 copyright date.

The Holden family of New Bedford exists happily until Mrs. Holden develops a heart condition. A divorcee new in town sets her sights on Mr. Holden, and "accidentally" causes his wife's death by spilling her medicine at a critical moment. The daughter, Effie, witnesses this and is outraged when her father marries this woman soon after. 
Effie abandons her own plans to marry a young clergyman, and remains at home to plot revenge. There is a bitter confrontation, with the implication that she kills both parents. She protests her innocence, stands trial, and is acquitted. The church supports her, to the point that it conspires to influence the jurors in her favor. Following the trial, Effie is shunned. She loses her young suitor and leads a lonely life as a social outcast.

The parallels to the Borden case are obvious. It is a simple play, offering revenge as a motive for the crime rather than greed. Lizzie is presented as a conventional romantic heroine; there is nothing odd about her (no eccentric quirks or haunting eyes); the family seems welladjusted until Mrs. Riggs enters the scene. The toning down of the characters and use of romantic conflicts are probably indicators of what producers thought would appeal to audiences at the time. The unscrupulous divorcee as stepmother is an interesting development, and quite a departure from the dull, innocuous Abby who appears in all the historical texts. It may signal cultural anxiety about disruptive, aggressive women who manipulate men to their own ends. Mrs. Riggs actually comes off worse than Effie. In a period of social and political unrest, the figure of the woman who threatens the stability of the patriarchal family by divorce, seduction, or parricide provides a focus for much unease. This was, after all, the 1930s. Women had 
recently won the right to vote. They were out in the workplace, and these were bad economic times. Political and economic competition and increased sexual freedom are threats to the status quo. It is not surprising to see them neutralized in popular entertainment.

Some years later, the Borden legend appears again as the basis for a mystery. Murder Takes the stage by James Reach is a low-key, uncomplicated play set in a summer theatre in a New England village. The owner of the building is a gracious old gentlewoman, Miss Liz Truesdale (also a prominent Fall River name). When one of the actors is murdered, it is revealed that years ago Miss Liz was tried for murdering her aunt and uncle in their bed, with an ax. She was acquitted, but of course is suspected now of committing this new crime. Miss Liz declares her innocence in both cases, and is exonerated when the real murderer is discovered--at least in part. The long ago murders remain a mystery in a one-dimensional story which does little more than keep the Borden legend in circulation.

A more ambitious play appears some years later. The Lights Are Warm and Coloured by William Norfolk was first presented in 1969, in St. Louis, and its first performance in Britain was in 1979. Dealing directly with the Borden case, it is set at Maplecroft (Lizzie's house) in 1905. A group of actors including Nance $O^{\prime}$ Neil, is visiting Lizzie. Before she appears onstage, they speculate whether she 
committed the murders. Lizzie is presented as a blunt, outspoken person who is not reluctant to address this issue. She is ostracized by the townspeople, but insists she is innocent, and claims to know the killer's identity but refuses to reveal it.

The actors then reenact significant scenes related to the murders, with Nance playing the part of Lizzie and Lizzie adding comments and a narrative structure. This technique has the potential to challenge the audience and raise provocative questions about character, but it does not happen here, as it does in Sharon Pollock's play, to be discussed later. Here, we simply get an effective representation of the fateful August 4 , of the investigation, and the trial, mainly using dialogue from the historical accounts. As this unfolds, Emma thinks she hears a prowler. When the actors leave, Bridget Sullivan breaks into the house. Lizzie had bribed her to disappear. They confront each other, each accusing the other of committing the murders. The question is left unresolved, and the play ends with Lizzie's current maid coming close to striking her before she leaves Lizzie standing alone onstage. It is an unsatisfactory ending, with vague implications about Lizzie's character.

In Lizzie Borden of Fall River (1976), she is a strongwilled, somewhat complex person, a feminist, kind to her aunt and rude to Abby. The household is tense, with stingy 
elders and hatred between Lizzie and Abby. The parents want Lizzie out of the house, but she resists. When the murder happens, it is offstage, but Lizzie appears guilty. At the end of the first scene, Lizzie stares at an axe, a rather clichéd warning of things to come. At the climax, Lizzie and Emma face each other. Emma claims she lied to save Lizzie's skin, and is convinced of her guilt. The curtain falls on Lizzie, sad and alone. The play's main function, besides entertainment, is clearly to perpetuate the legend.

None of these plays is particularly distinguished or memorable. All are based on the legend, and while not contributing anything new, they bring it to new audiences. one play, however, goes beyond the superficial story and characters to examine the legend thoughtfully and situate it in a contemporary context.

First performed in 1980 in Edmonton, Blood Relations is the work of Canadian playwright Sharon Pollock. The play was later produced in several other Canadian cities, and in Fall River in 1992. It appears in several anthologies, including a standard American college text for freshman literature courses. It is a work that is obviously taken seriously, and can reach a sizeable audience. The play is complex, with considerable range. It not only conveys Lizzie's story, but addresses issues of patriarchal tyranny, the construction of identity, the role of language, and moral responsibility, all related and all contemporary 
concerns. Whether it handles all these successfully is another matter, but it is well worth more attention. Here, Lizzie has become a worthy subject for intellectual scrutiny, and we see a blending of popular and highbrow concerns.

Set in the Borden house in 1902, the main characters are Lizzie and the Actress, who remains nameless but is based on Nance O'Neil. The production notes indicate that this is not a realistic play, and some of the characters are imaginary. Pollock draws on the biographical/historical sources which provide the family circumstances, Lizzie's social ambition, her love of animals, and her powerful will. She states unequivocally, "You can't make me do one thing that I don't want to do." The rumors of a lesbian relationship are taken seriously here. As in the prose literature, timing is all. Lizzie moves from heterosexual to homosexual when the culture allows it. Pollock also uses a variation of the famous rhyme not once, but twice, to keep us grounded in history:

Lizzie Borden took an ax

Gave her mother forty whacks, When the job was nicely done, She gave her father forty-one.

Pollock diverges from history in minor details like putting Abby's (nonexistent) brother at the scene rather than Sarah's brother John Morse, and in major ways like 
giving Lizzie a feminist sensibility. This is an updated Lizzie who is conscious of patriarchal oppression, a central issue in the play. When told it is time to get married and have a place of her own, she asks, "How would getting married get me that?" In response to a comment about a man not being likely to put up with her moods, she snaps, "What about me putting up with his!" Andrew wants to marry her off to a widower, and she resists energetically. When Lizzie muses about her dead mother, she sees her like a bird "caught in a horrible snare" (marriage? patriarchal society?) who had to die to escape it.

The play opens with the Actress rehearsing some lines from Shakespeare. An accused person is claiming innocence which "shall make / False accusation blush and tyranny / Tremble..." The choice of words is no accident. Tyranny becomes a major issue in the play. The way the lines are handled also raises questions about Lizzie's status. They are offered in a throwaway manner, with the Actress cursing and forgetting the rest of the speech. Pollock implies that Lizzie is innocent, or maybe she is not. Maybe it is all a representation, like a play on a stage. (And isn't that all we have when we consider Lizzie?) The difficulty in distinguishing between what is "real" and what is acting haunts this play.

The workings of tyranny are straightforward, however. Aside from Lizzie's acerbic comments, there is Abby's 
brother Harry, an obnoxious man whose opinions outline the limits placed on women by the patriarchal order. He says (without contradiction), "a woman is just like a horse...keep her on a tight rein" (24). And later, "if a man can't manage his own daughter, how the hell can he manage a business" (34). When Andrew kills Lizzie's birds, the act suggests he has the power of life and death in that household. Abby tells Lizzie, "your father keeps you. You know you got nothing but what he gives you. And that's a fact of life" (41). If that isn't chilling enough, she adds, "Lizzie, you got no rights" (42). Indeed, Lizzie's only hope for independence rests on inheriting Andrew's money, and her plight is presented sympathetically.

Her situation is complicated by the bond between father and daughter. They express affection for each other in words, but these often have an unpleasant edge. Lizzie observes of the ring she gave him (ostensibly a loving gesture), "see how it bites into the flesh of your finger." There is also a great deal of physical violence onstage, which belies the affectionate words and raises doubts about the reliability of language. Lizzie smashes plates and cries; she insults Abby, and Andrew slaps Lizzie. He grabs her arm and she hits him. He pushes her to the floor. In another scene, he slaps her. Then he angrily smashes a hatchet into a table and goes out to chop the heads off her birds. 
Hatred, love and tension coexist in this house in a poisonous atmosphere. While there are no overt allusions to incest, an extreme form of abuse in the patriarchal family gone bad, there are hints. The title of the play itself suggests a provocative ambiguity. In the Borden house, excess is the order of the day. As Shelley noted, "Incest is like many other incorrect things a very poetical circumstance. It may be the excess of love or hate" (Worton 107), or we might add, the excess of a system which makes women the property of their fathers.

Lizzie's character sends signals that she may be a victim of incest, and these relate to the issue of identity. In the most basic sense, interest in the Borden case involves curiosity about who Lizzie was, what kind of person she must have been to do what she did, and we see all these writers exploring this question. Pollock, however, questions the very concept of identity, or at least how it is currently considered. One of the most striking aspects of this play is the constant shift in characters' roles. It disorients the audience. The Lizzie character initiates a game in which the Actress plays Lizzie, Lizzie plays Bridget, and sometimes they revert to their "original" character. In effect, we have a play within a play, with Lizzie providing commentary.

At the beginning of Act 2 , both Miss Lizzie/Bridget and Actress/Lizzie are speaking as Lizzie, conversing with each 
other, creating a disturbing effect. The Actress becomes quite convincing as Lizzie, implying that Lizzie is not unique. This also suggests that the individual is in many ways a social construct, formed by roles and expectations. Much of what we think of as Lizzie is a changing, unstable set of words and mannerisms. Language as a means of asserting truth and self becomes suspect here. This is clearly a critique of the notion of a fixed identity found in so much of contemporary literary theory, as well as in the works of some avant-garde or postmodern artists. Madonne Miner takes it even further, to claim that the "slipperiness of self" and interchangeability of the characters point to Lizzie's "non-deviance." She states that "such acts might be committed by any nineteenth-century woman." This seems excessive to me, first because it is foolish to claim that all women of the period had the same experiences and responses, and second because there is a world of difference between being capable of an act and performing it. I do agree that the play speaks to a sense of oppression that many women share, and that some, like Miner, would like to make excuses for Lizzie's crime and view it as a political act. Despite Miner's assertions, however, it seems to me that the play presents Lizzie as deviant, and not the Actress.

The problem of identity is approached in more traditional ways as well, through Lizzie's lines. A grown 
woman, she keeps searching for a sense of self. Pollock implies there is no essential self. Also, if language is used to construct or find the self, and it is governed by patriarchy, how could it help Lizzie, unless she develops a new consciousness, which does not happen here. She asks, "do you suppose there's... a magic formula for being 'a woman'?" and fears she missed out on it (36). Lizzie asks her father if she is like him or her mother--"I must be like someone" (57). Arguing with Abby, she says, "I'm supposed to be a mirror. I'm supposed to reflect what you want to see, but everyone wants something different. If no one looks in the mirror, I'm not even there, I don't exist!" (39). She also asks worriedly, "Am I different?" (49). Not only do these lines express a search for self, but they may also reflect the consequences of incest. Lizzie's anger, her keen sense of being different, and her need to belong are all characteristics which have been identified in female victims of incest (Justice 182-3). On the one hand a critique of identity, the play also suggests that something unnamed has caused her to lose herself. Theorizing about the self is an interesting intellectual exercise, but even those who agree with Pollock's critique of the unitary self tend to possess a coherent sense of who they are. The Lizzie character here seems to have completely lost that sense. This is an interesting representation, as I strongly suspect that the historical Lizzie who bought and furnished 
Maplecroft, renamed herself Lisbeth, and lived out her days in Fall River, had no doubt about who she was. An insecure person could never have done that.

However much a victim Lizzie may be, in this play she is also a killer, and the issue of moral responsibility is raised. She is frequently asked, "Lizzie, did you?" and avoids answering because this play is about so much more than that. I think the audience does want to know the answer, and the Actress expresses its feelings when she says, "If you didn't I should be disappointed... and if you did I should be horrified." But the real question is, even if she committed the murders, what is the extent of her guilt?

In a dialogue with Dr. Patrick she articulates some of the complexities of her dilemma. He tries to soothe her with clichés like "all life is precious and unique," but she exposes his triteness and hypocrisy. She asks, is it so wrong to kill someone wicked, like Attila the Hun? If a physician must choose between saving two people, should the decision be based on age or virtue or what? Why does the State consider killing innocent people in a war acceptable? Her questions reveal the cracks in the smug platitudes of society. However, her conclusions that "not all life is precious" and "bad things...must die" are chilling. The prospect of Lizzie having the power of life and death over her household is not any more attractive than Andrew's hold 
on it.

The strong emphasis on the social construction of identity begs the moral question. At the end, Lizzie tells Emma, "Did you never stop and think that if I did, then you were guilty too?" Lizzie claims she was Emma's puppet, but this is not borne out in the play. In that startling final moment, the Actress says, "Lizzie, you did." Lizzie responds, "I didn't...you did." The stage directions have the Actress looking at the audience, but do not indicate where Lizzie is looking. It would be effective to have her do likewise, since the implications of this verbal exchange are clear. Her gaze at the audience would recognize the very real desire for this story to be told and retold. Aren't we more than just a group of "innocent bystanders?" Lizzie has been acted upon by powerful social forces. She has been infected with the materialism of her society and the violence of her home. Her actions did not take place in a vacuum. Whether these factors alleviate her guilt is a question Pollock proposes but does not resolve. She shows that viewing Lizzie as an autonomous actor in this drama is too simplistic. However, Miner overstates the case when she claims that these characters "do not author their own meanings and actions." (Later she says Lizzie authors herself as "other.") She implies that patriarchal society and not Lizzie is responsible. This takes victimization too far. One wonders why all women then were not swinging axes 
at fathers who oppressed them, and why stop with fathers? The fact remains that few women took such drastic action. Many women in the nineteenth century did work very hard to change and improve the social and political situation of women, but changing the system, while more significant, lacks the punch of parricide. The question of responsibility raised in the play is left to each of us to determine, and Pollock deserves credit for raising it effectively. Rather than concentrating only on the murders and whether Lizzie did them, Pollock goes beyond producing a shudder to provoking thought, exploring key ideological issues of our time, and relating them to our past.

It was only a matter of time before Lizzie reached the television screen. A story about the case appeared on Alfred Hitchcock Presents in 1956 (Flynn 83-4). I also recall seeing an I Love Lucy episode where Lucy, on a crosscountry automobile trip, found herself with a woman suspected of being an axe murderess, clearly an evocation of Lizzie. Considering how classic television programs are recycled on cable, we can assume that a considerable audience has viewed and will view these episodes. The fullest account of the legend came in 1974, in william Bast's made-for-TV movie, The Legend of Lizzie Borden, starring Elizabeth Montgomery, who even slightly resembles her. At present, the movie is not available commercially. 
However, since its network premier, it has received a lot of play on cable.

The film begins with the day of the murders and ends with Lizzie's acquittal. It opens with the statement that much of it is based on fact. Anyone familiar with the case also sees that there is plenty of conjecture, the most striking being Lizzie's execution of the murders onscreen. But then, legend is situated between history and myth. The troubled family life of the Bordens is revealed, as is Lizzie's frustration and desire for social prestige. The ingredients of standard family melodrama are in place. She fights with Abby and Andrew about money, and complains she is suffocating. This implies a desire for fulfillment which is being stifled in the Borden household. A thin thread of feminism runs through the story. Later, Mrs. Knowlton, the prosecutor's wife, is seen at home, expressing sympathy for Lizzie's plight as a woman.

Lizzie has other troubles as well. Her reputation as a shoplifter comes into play, another sign of female frustration. We see her steal an axe. The merchant does not see what she takes, but tells an indignant witness that everyone knows about Lizzie, and they just send Andrew the bill. While one is watching the film and swept along with the story, this element is not bothersome, but in retrospect it creates a flaw in the plot. How will the merchant bill Andrew, and if he discovers what was stolen, won't that 
solve the mystery of the murders?

At a dramatic moment we see Lizzie wielding her prize. In the courtroom scene near the end, just before the fury announces its verdict, there is a flashback to August 4 . We see Lizzie undress completely before each murder, and then wash away the blood. The point of view shifts here, as the camera follows Lizzie, allowing us to see her, and then becomes her eyes, so that spectators are drawn to join her in her gruesome acts. Each time, she gets the attention of her victim and then strikes. It is a sadistic touch. Because of network standards, the viewer does not see much nudity, of course, and is spared the full bloody horror of the murders. Still, the effect is powerful, and the camera positions raise questions about the viewer's perspective and identification with characters.

First, one wonders if any viewers would tend to identify with Lizzie. The narrative presents a deeply troubled and frustrated woman who is a victim of patriarchal society. As an adult, her family oppresses her. Other flashbacks show trauma in childhood as well. When Andrew was working as a mortician, little Lizzie saw him preparing a corpse. He forced her to touch it, and the terrified child accidentally pulled a tube out of the body, splashing blood around, and on herself. Her screams resonate into her adulthood. The pattern of flashbacks--to the childhood scene, to family quarrels, to the murders--implies a 
connection. This is a victim acting out her rage, which was nurtured in the bosom of her family. Like the zombies in Night of the Living Dead, she does not "stand for a threat to social order from without." She is "directly animated and possessed" by the forces that produce the social order (Shaviro 86). It seems likely to me that some viewers could indeed identify with her.

However, the film also takes pains to show her otherness. When Emma comforts Lizzie, she tells her she is "special." This is not subtle, and seems to be a code word for strangeness. There are several points in the film where Lizzie gets a sinister look on her face, and maintains an ominous and mysterious silence. Surely these moments create distance, so that if one felt some connection or sympathy, it is severed here. This is characteristic of the ambivalence in the story. Lizzie killed her father, but loved him, too. We see her sneaking downstairs at night to kiss his corpse as it rests in the family home the night after the murders. Early on, Emma asks, "Lizzie, did you kill Father?" Lizzie denies it. Then, at the end, Emma says she will ask only once more and never again. This is right after the trial, and Lizzie does not answer. She is caught in a freeze frame, while in the background children's voices sing the famous rhyme. The ambivalence she embodies suggests not only our feelings about family, but also the tantalizing, almost childlike dream of getting away with 
murder .

So far we have only considered identification with Lizzie. Some might identify with Abby and/or Andrew, and be alienated from Lizzie. To assume that women will identify with Lizzie or Abby, and men with Andrew is simplistic. I have already referred elsewhere to Carol clover's questioning of assumptions about gender and identification. She states that usually "angry displays of force" are male, and "abject terror" is female (51). So if we follow that formula, men would identify with Lizzie, whose aggressive act makes her masculine. Clover reminds us that "the idea that appearance and behavior do not necessarily indicate sex--indeed, can misindicate sex--is predicated on the understanding that sex is one thing and gender another; in practice, that sex is life, a less-than-interesting given, but that gender is theater" (58). The issue of identification gets complicated, and even more so when we deal with Lizzie, who is both masculine/dangerous and feminine/terrified in this film, which contains elements of the family melodrama, slasher, and horror genres.

In his writing about horror films, steven Shaviro suggests a rather different way to think about the contradictory positions of both Lizzie and the viewer. He observes that cinematic pleasure "can just as well be linked to the destruction of identification and objectification, to the undermining of subjective stability" (42). In fact, 
"cinema's greatest power may be its ability to evacuate meanings and identities, to proliferate resemblances without sense or origin" (254). By now, even though a historical Lizzie once existed, the representations we see have been cut loose from the source. She is an unstable character in the film, both murderer and victim, ordinary and "special." That has interesting implications for the viewer. Her passion involves no closure. Looking at her silent face at the end, the viewer is left without resolution of the tensions created in the story. I think it corresponds to what Shaviro describes as "the ecstasy and terror of abjection" (155). Whatever loss there is of certainty and the ability to "know" a character (and therefore feel a sense of control), there is the pleasure of the visual, the power of images to provide a fleshly reaction. Shaviro notes that film theory, "beneath its claims to methodological rigor and political correctness...manifests a barely contained panic at the prospect... of being affected and moved by visual forms. It is as if there were something degrading and dangerous about giving way to images, and so easily falling under their power" (13-4). Horror films "short-circuit the mechanism of fantasy altogether." They "incise...imaginings" in the viewer's flesh, and have a visceral effect (100). It may well be this quality that makes the movie popular and compelling. The powerful, forbidden, and thrilling force of the images of Lizzie keeps 
the fascination of the audience alive. 
AFTERWORD

"To travel hopefully is a better thing than to arrive." Robert Louis Stevenson.

When I began this project, I did not know where it would take me, even though I started with some assumptions. While I had my suspicions that the "real" Lizzie is unrecoverable, I found more, and more interesting Lizzies than I had bargained for. Tracing her representations, each marked by its time and place of creation, leads unavoidably to considerations of society and culture. And by viewing these texts through various theoretical lenses (feminist, literary, historical, media) the relation of this pop culture figure to issues of gender, family, class, justice, identity, psychology, genre studies, and taste becomes evident. The associations she embodies are rich, and her appeal to diverse writers and readers is now easier for me to understand. The very lack of reliable information about her makes her an intriguing subject. As writers look for someone to write about, there in the landscape is Lizzie Borden.

Such is her continued presence that it was possible to hold a conference at Bristol Community College in 1992, the centennial of the crime, and attract over four hundred people. I had the pleasure of being involved in the 
conference as a planner, presenter, and session chair. I suspect that the administration may have been a little anxious at first about this gathering taking on a ghoulish cast, but it was an extraordinarily pleasant, cheerful affair. For three days people from all over the United States, and a few from Canada, Great Britain, and Australia gathered in Fall River to talk about the Borden case. Professors, lawyers, publishers, journalists, physicians, and people from many walks of life who do not usually attend such meetings got together and discussed Lizzie from every angle imaginable. The community of Borden fans is diverse and thriving. And now it even has its own newsletter, the Lizzie Borden Quarterly, published in Fall River. This augurs well for the continuation and development of the legend.

My study, then, is just a beginning. I did not attempt to include all the Borden texts and related performances, so there is more work to be done. There is a children's book on Lizzie's trial for grade 5 and up, which opens a whole new area of inquiry. Both Jack Beeson's opera and Agnes De Mille's ballet invite closer study. Just recently the Fall River Historical Society published Hosea Knowlton's papers. Mr. Knowlton was the chief prosecutor, and his personal correspondence and notes about the trial, as well as advice sent to him from professionals and citizens across the country, are now available for the first time. All of these 
deserve attention. And then there is nationally known criminologist James Starrs, who dug up Zachary Taylor and has been trying for several years to get permission to exhume the victims' skulls and test other material evidence. So far he has been refused, but who knows what may develop. Then there are studies of audience which could be conducted. We know so little about media audiences, and there has been no research on Borden fans. The conference in 1992 provided a self-identified group of fans, and the mailing list probably still exists. The Lizzie Borden Quarterly would be another way to reach this group with a questionnaire. Fall River high school students would be another interesting group to study. Some Durfee High School graduates have told me about a history course which focuses on Lizzie. It would be worthwhile to survey students taking the course, as well as another group, to learn about their perceptions, attitudes, and beliefs regarding Lizzie and related issues.

Like the figure of Lizzie, the study of her legend can take on a life of its own. I come to the end of this project with no grand theory but a conviction that while the iconic Lizzie may be as simple and direct as the doggerel verse, the textual works can get very complex. I like the subversiveness in the figure which never stops raising questions. On the one hand, she was acquitted of the murders, and at least for me, was likable on two counts, 
because she was kind to animals and showed amazing strength by staying in Fall River after the trial. But anyone contemplating Lizzie must eventually confront another image. The evidence showed that Abby Borden faced her murderer. Could Lizzie really have stood over her elderly stepmother and planted the axe in her head? Was she so damaged by her family that she exploded in violent anger? Was she cruel and wicked? Many references to the murderer stress the monstrousness of the act, placing it in the realm of the "inhuman." Some of the comments about Lizzie's eyes also imply some inhuman quality. This seems to me a mistaken view. Everything humans do is "human," from the kindest to the cruelest acts. This terrifying and wonderful range is one of the things that makes humans so interesting, and the figures who stand at the ends of the spectrum tend to capture our imagination, finding their way into stories and legend. Lizzie is extreme, but she is also an ordinary human. She gives the lie to romanticized notions of what it means to be human, and invites us to look unflinchingly at the question, much as she gazes back at us in the wellknown photographs. Her story is the stuff of literature, whether it is popular or of a grander sort. She is a discursive space where we face fears and fantasies, and escape to safety. As we create her anew, we interrogate the past and incorporate pieces of it into the present. We recontextualize her to meet our current needs. She is not 
finished; we never arrive, but keep moving toward her. The story continues. 


\section{BIBLIOGRAPHY}

"Acquittal of Miss Borden." New York Times 21 June 1893: 4 .

"Affirmations." New Age Encyclopedia. Ed. J. Gordon Melton, Jerome Clark, and Aidan A. Kelly. Detroit: Gale Research, 1990.

Bakhtin, Mikhail M. The Dialogic Imagination: Four Essays. Trans. Caryl Emerson and Michael Holquist. Ed. Michael Holquist. Austin: U of Texas P, 1981.

Baldasty, Gerald J. The commercialization of News in the Nineteenth Century. Madison: U of Wisconsin P, 1992.

Berger, John, et al. Ways of Seeing. Harmondsworth: Penguin, 1972.

Bierstadt, Edward Hale. Satan Was a Man; A Novel of Murder. New York: Doubleday, Doran, 1935.

"Big Gain for Lizzie Borden." New York Times 13 June 1893: 9.

Bixby, A.L. To Lizzie. Rabun Gap, GA: Romar Books, 1992.

Bloch, Robert. "Lizzie Borden Took an Axe..." Lizzie Borden Quarterly 2.1 (1994): 8-12.

Bocharov, Sergey. "Conversations with Bakhtin." PMLA 109 (1994): 1009-24.

Book Review Digest. New York: H.W. Wilson, 1905-

"Borden Murder Trial Begun." New York Times 6 June 1893: 2 .

"Bordenmania: Impact of Lizzie Borden Case." Encyclopedia of American crime. Ed. Carl Sifakis. New York: Smithmark, 1992.

"Bridget Sullivan a Witness." New York Times 8 June 1893: 8 .

Brown, Arnold. Lizzie Borden: The Legend, the Truth, the Final Chapter. Nashville: Rutledge Hill P, 1991. 
Carlisle, Marcla R. "What Made Lizzie Borden Kill?" American Heritage July-August 1992: 66-72.

Carter, Angela. "The Fall River Axe Murders." The Black Cabinet. Ed. Peter Lovesey. New York: Carroll \& Graf, 1989. 38-56.

Cawelti, John G. Adventure, Mystery, and Romance. Chicago: U of Chicago P, 1976.

Clover, Carol J. Men, Women, and Chain Saws: Gender in the Modern Horror Film. Princeton: Princeton UP, 1992.

Collins, Jim. Uncommon cultures: Popular Culture and Post-Modernism. New York: Routledge, 1989.

Colton, John, and Carlton Miles. Nine Pine street: A Play in Three Acts and Epilogue. New York: Samuel French, 1934 .

"Conduct of the Borden Trial." New York Times 20 June $1893: 4$.

Davis, Amma A. "Narrative Reactions to Brutal Murders: A Case Study." Western Folklore 49 (1990): 99-109.

De Mille, Agnes. Lizzie Borden: A Dance of Death. Boston: Little, Brown, 1968.

Dickinson, Asa Don. The Best Books of the Decade, 19261935. New York: H.W. Wilson, 1937.

Dimock, Wai-Chee. "Feminism, New Historicism, and the Reader." American Literature 63 (1991): 601-22.

Douglas, Susan J. "Notes Toward a History of Media Audiences." Radical History Review 54 (1992): 127-38.

Engstrom, Elizabeth. Lizzie Borden. New York: Tom Doherty Associates, 1991.

Epstein, william H., ed. contesting the Subject: Essays in the Postmodern Theory and Practice of Biography and Biographical criticism. West Lafayette: Purdue UP, 1991.

Flynn, Robert $A$. The Borden Murders: An Annotated Bibliography. Portland, ME: King Philip Publishing, 1992 .

Gray, William S. The Reading Interests and Habits of 
Adults; A Preliminary Report. New York: Macmillan, 1929 .

Hart, James D. The Popular Book: A History of America's Literary Taste. Berkeley: U of Cal. P, 1963.

Hart, Jonathan. "New Historicism: Taking History into Account." Ariel 22 (1991): 93-107.

Hunter, Evan. Lizzie. New York: Arbor House, 1984.

"Introductory Essay." New Age Encyclopedia. Melton, J. Gordon, ed.

Jones, Ann. Women who Kill. New York: Fawcett Crest, 1980.

Jordan, Elaine. "The Dangers of Angela Carter." New Feminist Discourses; Critical Essays on Theories and Texts. New York: Routledge, 1992. 119-31.

Justice, Blair, and Rita Justice. The Broken Taboo: Sex in the Family. New York: Human Sciences P, 1979.

Kelly, Tim. Lizzie Borden of Fall River: Drama in Two Acts. Denver: Pioneer Drama Service, 1976.

Kent, David. Forty Whacks; New Evidence in the Life and Legend of Lizzie Borden. Emmaus, PA: Yankee Books, 1992 .

---, ed. Lizzie Borden Sourcebook. Boston: Branden Pub. Co., 1992 .

Kobre, Sidney. Development of American Journalism. Dubuque: Wm. C. Brown, 1969.

Krauss, Jennifer. "Angela Carter." Short story Criticism. Detroit: Gale Research, 1993. vol. 13.

Kunitz, Stanley J., and Howard Haycraft, eds. Twentieth Century Authors. New York: H. W. Wilson, 1942.

The Legend of Lizzie Borden. Videocassette. Dir. William Bast. With Elizabeth Montgomery. George Lemaire Productions in association with Paramount Pictures, 1975.

Lesser, Wendy. Pictures at an Execution. Cambridge: Harvard UP, 1993.

Lincoln, Victoria. A Private Disgrace; Lizzie Borden by Daylight. New York: International Polygonics, 1986. 
"Lizzie Borden in a Faint." New York Times 7 June 1893: 2 .

"Lizzie Borden is Acquitted." New York Times 21 June 1893: 1 .

Lodge, David. After Bakhtin; Essays on Fiction and criticism. London: Routledge, 1990.

Logan, Andy. "Slouching Towards the Senate." New Yorker 2 Nov. 1992: 46.

Lowndes, Marie Belloc. Lizzie Borden: A Study in Conjecture. New York: Longmans, Green, 1939.

"Lowndes, Mrs. Marie Adelaide (Belloc)." Twentieth Century Authors. Ed. Stanley J. Kunitz and Howard Haycraft. New York: H.W. Wilson, 1942 .

Lutzeler, Paul Michael. "Fictionality in Historiography and the Novel." Never-ending Stories; Toward a critical Narratology. Ed. Ann Fehn, Ingeborg Hoesterey, and Maria Tatar. Princeton: Princeton UP, 1992. 30-40.

McNamara, M. Eileen. "Was Lizzie Borden the victim of Incest?" Ryckebusch 39-45.

Melton, J. Gordon, Jerome Clark, and Aidan A. Kelly, eds. New Age Encyclopedia. Detroit: Gale Research, 1990.

Miner, Madonne. "Lizzie Borden Took an Ax': Enacting Blood Relations." Literature in Performance 6.2 (1986): 10-21.

Mitchell, Betty. "The True Lizzie Borden." Ryckebusch 201-10.

"More Talk About Hatchets." New York Times 11 June 1893: 8 .

Morris, Virginia B. Double Jeopardy: Women who Kill in Victorian Fiction. Lexington: UP of Kentucky, 1990.

Morson, Gary S., and Caryl Emerson. Mikhail Bakhtin: creation of a Prosaics. Stanford: Stanford UP, 1990.

"Mr. Borden's Skull in Court." New York Times 14 June $1893: 8$.

Mussell, Kay. Fantasy and Reconciliation: Contemporary Formulas of Women's Romance Fiction. Westport, CT: Greenwood P, 1984 . 
---. "Romantic Fiction." Handbook of American Popular Culture. Ed. M. Thomas Inge. 3 vols. Westport, CT: Greenwood P, 1980 .

Norfolk, William. The Lights Are Warm and Colored: A Play. London: Samuel French, 1980.

o'Brien, Sharon. "Feminist Theory and Literary Biography." Epstein 123-33.

Palmer, Jerry. Potboilers: Methods, Concepts and Case studies in Popular Fiction. New York: Routledge, 1991.

--- Thrillers: Genesis and structure of a Popular Genre. New York: St. Martin's P, 1979.

Pearson, Edmund. Five Murders: With a Final Note on the Borden Case. New York: Doubleday, Doran, 1928.

--- More Studies in Murder. New York: Harrison Smith and Robert Haas, 1936.

--- Murder at Smutty Nose, and other Murders. New York: Doubleday, Page, 1927.

--- Queer Books. New York: Doubleday, Doran, 1928.

---. Studies in Murder. New York: Macmillan, 1924.

--- The Trial of Lizzie Borden. New York: Doubleday, Doran, 1937.

"Pearson, Edmund Lester." Twentieth Century Authors. Kunitz, Stanley J., ed.

Plath, Sylvia. The collected Poems. Ed. Ted Hughes. New York: Harper \& Row, 1981.

Pollock, Sharon. Blood Relations and Other Plays. Edmonton: Newest $P, 1981$.

Poovey, Mary. "Cultural Criticism: Past and Present." college English 52 (1990): 615-25.

Porter, Edwin $H$. The Fall River Tragedy: A History of the Borden Murders. Portland, KE: King Philip Publishing, 1985.

"Prussic Acid in the Case." New York Times 15 June 1893: 9.

Radin, Edward D. Lizzie Borden: The Untold Story. New 
York: Dell, 1961.

Radway, Janice A. Reading the Romance: Women, Patriarchy, and Popular Literature. Chapel Hill: U of North Carolina P, 1984 .

Reach, James. Murder Takes the Stage: A Mystery Play in Three Acts. New York: Samuel French, 1957.

"Ready for the Arguments." New York Times 17 June 1893: 1.

"Reich, Wilhelm." New Age Encyclopedia. Melton, J. Gordon, ed.

Ronan, Stephen. our Lady of Fall River. Berkeley: Ammunition P, 1983.

Rosenberg, Bruce A. Custer and the Epic of Defeat. University Park: Penn. State UP, 1974.

Ross, Valerie. "Too Close to Home; Repressing Biography, Instituting Authority." Epstein 135-65.

Russett, Cynthia Eagle. Sexual science; The victorian construction of Nomanhood. Cambridge: Harvard UP, 1989.

Ryckebusch, Jules R., ed. Proceedings: Lizzie Borden Conference. August 3-5, 1992. Fall River: Bristol Community College, 1993.

Samuels, Charles, and Louise Samuels. The Girl in the House of Hate. Mattituck, NY: Aeonian P, 1953.

Satterthwaite, Walter. Miss Iizzie. New York: St. Martin's P, 1989 .

Shaviro, Steven. The Cinematic Body. Minneapolis: U of Minnesota P, 1993.

Smith-Rosenberg, Carroll. "Writing History: Language, Class, and Gender." Feminist studies, Critical Studies. Ed. Teresa de Lauretis. Bloomington: Indiana UP, 1986.

Spiering, Frank. Lizzie. New York: Random House, 1984.

Stephens, Mitchell. A History of News: From the Drum to the Satellite. New York: Penguin, 1988.

"Struck by a Jealous Husband." New York Times 1 Sept. 1879: 5 . 
Sullivan, Robert. Goodbye Lizzie Borden. New York: Penguin, 1974 .

Thomas, Brook. The New Historicism and other old-Fashioned Topics. Princeton: Princeton UP, 1991.

Tuchman, Gaye. Making News: A Study in the construction of Reality. New York: Free P, 1978.

Walbridge, Earle F. "Pearson, Edmund Lester." Dictionary of American Biography. New York: Charles Scribner's Sons, 1958.

Whitman, Ruth. "History, Myth, and Poetry: Writing the Historical Persona Poem." Iowa English Bulletin 35 $(1987)$ : 65-73.

--- The Passion of Lizzie Borden: New and Selected Poems. New York: October House, 1973.

"Will It Remain a Mystery?" New York Times 17 June 1893: 4 .

Williams, Joyce G., J. Eric Smithburn, and M. Jeanne Peterson, eds. Lizzie Borden: A Case Book of Family and crime in the 1890s. Bloomington: T.I.S. Publications, 1980 .

Wilson, Rob. "Producing American Selves; The Form of American Biography." Epstein 167-92.

Worton, Michael. "Speech and Silence in The Cenci." Essays on Shelley. Ed. Miriam Allott. Totawa, NJ: Barnes \& Noble, 1982. 105-24. 